\title{
Jean Etchepare Konplaintak 1873-1890
}

\author{
PATRI URKIZU \\ (UNED)
}

\begin{abstract}
AITZIN-SOLAS
Eta Kain mintzatu zen bere anaia Abelekin. Eta nola larrean baitziren, altxatu zen Kain bere anaia Abelen kontra eta hil zuen. Eta Eternalak erran zioen Kaini:

—Non da Abel hire anaia?

Zeinak ihardetsi baitzuen:

—Etzeakiat, ene anaiaren guarda naiz ni?

Eta erran zuen Jainkoak:

- Zer egin duk? Hire anaiaren odolaren boza lurretik oihuz ziagotak niri. Orai bada madarikatua izango aiz lurreko aldetik ere, zeinak ideki baitu bere ahoa errezibitzeko hire eskutik hire anaiaren odola. Lurra jorratuko duan orduan, eztarok errendatuko gehiago bere berthutea: oraino herraturik ihesi ibiliko aiz lurraren gainean.

Eta Kainek erran zioen Eternalari:

— Nik jasan ahal dezakedan baino handiago da ene punizionea.

(Ethorkia, IV, 8-13)

Le dix-huitième siècle, c' est là une partie de sa gloire, a aboli la torture; le dix-neuvième siècle abolira la peine de mort.
\end{abstract}

Victor Hugo, La peine de mort (15-IX-1848) 
Cesare Beccaria Milango markes iluministak idatzitako Dei delitti e delle pene (1764) liburu ttipiak Europa osoan arrakasta handia lortu zuen, eta batez ere Frantzian ilustratu eta entziklopedisten artean. Heriotze zigorrak gizarte arazoak konpondu beharrean okertu egiten zituela, zioen. Gainera, bizitza eta heriotza Jainkoaren dohainak zirenez, zein eskubidez gizonak ausartzen ziren sartzera beren alorrak ez ziren egitekoetan?

Ia mende bat iragan zen Victor Hugok bere aldetik sorkuntza eta bestelako obretan lekukoa hartu arte, bereziki Kondenatu baten Azken Eguna eleberritxo$\mathrm{an}^{1}$. Parlamentuan saiatu zen ere hitz sutsuz politikariak bere ideietara erakartzen, baina tamalez frantses gizarteak kasu egin arte urte anitz igaro behar izan ziren, heriotze zigorraren deuseztatze osoa Robert Badinter-en eskutik 1981eko urrilaren 9an lortu baitzen.

Hiru urte lehenago Espainian onartu 1978ko Konstituzioak hamabostgarren artikuluan honakoa zioen, Queda abolida la pena de muerte, salvo lo que puedan disponer las leyes penales militares para tiempos de guerra. Halaber salbuespen hau ere Código Penal Militar-etik 1995eko azaroaren 17an kendu eta ezabatu zen.

Beraz ikusten da Beccaria eta Hugo aitzindariak izan zirela, gizarte justoago baten borrokalari eta ameslari. Aitzindari. Haien ondorengo gizakien krimen eta zigor hunkigarrien zerrenda luzea eta ia etengabea izan da, eta tamalez oraindik egun ere zenbait herrialdetan zigor gorena tinko eta bidegabeki dirau.

\section{Zer diren konplaintak}

COMPLAINTE, nigar-kantu; — chant funèbre, hil-eresi.

Honelaxeko ordainak ematen dizkigu André Tournier eta Pierre Lafitteren artean burutu frantses-euskara hiztegiak ${ }^{2}$. Orotariko Euskal Hiztegiak ez dakarren arren konplainta hitza jasorik, aurkezten dugun koplariak, alegia, Jean Etcheparek 1873an jadanik badarabilenez ez dugu baztertuko.

Heriotza eta literaturak, gauza ezaguna da, harreman zuzenak izan dituzte mendeetan zehar. Joseph Le Floch-ek ${ }^{3}$ dioskunez mendebaldeko hirietako kaleetan zehar eta plazetan kantari ibiltzen ohi ziren bertso saltzaileak erdi aroko juglar berriemaileen ondorengotzat har ditzakegu. Eta kantatzearekin batera saltzen zituzten bertso-paperak era orotarikoak izan zitezkeen: gerra kantak, amodiozkoak, kantikak, noelak, santuen bizitzak, irri eta ziri egitekoak, urkamendi eta gilotinako ixtorioak kontatzen zituztenak...

Azken hauetan arreta pixkat paratuz ohartuko gara jada XI. mendean Codex Calixtinus-ean aipatzen zaigula Urkatuaren Miraria, zein XIII. mendean Al-

\footnotetext{
${ }^{1}$ Victor Hugo, 1829, Le dernier Jour d'un condamné. Paris: Gosseling et Bossanges.

2 André Tournier \& Pierre Lafitte, 1954, Lexique français-basque. Bayonne: ed. Herria, 84.

3 Joseph Le Floch, 2001, «Chanteurs de rue et complaintes judiciaires. Quelques remarques à propos des complaintes françaises», Histoire et justicie, Panorame de la recherche. Le Temps de l'Histoire, nov. 155-168.
} 
fonso X. jakitunak bere Cantigas a Nuestra Señora liburu ospetsuan jadanik jasotzen duen. XV. mendeko bukaeran moldatu zituela François Villon poetak bere epitaphe edo ballade des pendus ospetsua eta XVI. mendean, 1587an hain zuzen, Maria Stuart hil zutenean, historialariak dioenez Parise beterik zegoela gertakizun triste hari buruzko bertso-paperez, pasquils [complaints], placcards, tombeaux et discours sur cette morte violent voloient..

Airean zebiltzan bertso-paperak, eta hori dela eta frantsesek izen hori emango diete, hain zuzen: feuilles volantes...Espainian hedatu ohi zirenei «pliegos de cordel» deitzen zitzaien, eta jada XVI. mendeaz geroztik hilketak eta gertaera odoltsuak kontatzen zituztenak ere ez ziren gutxi ${ }^{4}$.

XVIII. mendean Louis-Sébastien Mercier-ek, Pariseko kronista ospetsu batek kale kantariei buruzko honako irudia utziko digu:

Un parricide, un empoisonneur, un assasin, le lendemain, que dis-je, dès le jour même de leur supplice, enfantent des complaintes qui ont chantées dans tous les carrefours et composées par les chanteurs du Pont-Neuf. ${ }^{5}$

Alegia, gurasoen hiltzaile baten, pozointzale baten eta asesino baten hilketaren biharamunean edo egun berean hasiak zirela plaza eta ixkin orotan PontNeuf-eko kantariek moldaturiko konplaintak saltzen eta kantatzen.

Euskal Herrian ere ez ziren ezezagunak honelako kantak, horixe baitio Francisque Michelek bederen, comme ailleurs, les complaintes composées dans le Pays Basque à l'occasion de crimes célèbres et du supplice de leurs auteurs sont en grand nombre ${ }^{6}$, hots, ugariak zirela ere gurean hilketen ondoren urkamendiko edo gilotinako zigorraren okasiorako moldatzen ohi ziren bertsoak eta kantak. Hauxe dio 1857an Michelek, baina tamalez ez dira asko iritsi zaizkigunak ${ }^{7}$, arruntak ziren bertso haietarik.

\section{Nor den Jean Etchepare}

Gaur hemen aurkeztuko dugun Jean Etchepare donapaleutar bertsogilearen kantu berrien multzoa ildo beretik doa. Baina nor da Jean Etchepare delako hori? Xabier Kaltzakortak ${ }^{8}$ Jon Bilbaoren Bibliografia aipatu ondoren, hauxe esaten digu:

Lau bertsopaperen egilearen izen-deiturak eta jaioterria besterik ez dakigu. Nondik atera ote zuen Jon Bilbaok Jean Etchepare honen jaioterria Donapaleu zela? Guk, egia esan, ez daukagu inolako daturik. Dakiguntxoa da gure euskal li-

${ }^{4}$ Anónimo: «Coplas hechas sobre un caso acontecido en Yerez de la Frontera de un hombre que mató a 22 personas.», s. XVI. Ik: Carolina Lecoq, 1988, «Los pliegos de cordel» en las bibliotecas de Paris. Madrid: Printing Books, s.a., 72

5 Tableau de Paris, 1788. (Paris: Horizons de France, 1947, 156.)

${ }^{6}$ Francisque Michel, 1857, Le Pays Basque... Paris: F. Didot, 423.

7 Prestatu berri dugun Urkamendiko baladak deitu edizio batean 40 bildu ditugu.

8 Xabier Kaltzakorta, 2000-2, «Jean Etchepareren cantu dolorosac», KARMEL, Bilbao 35-55. 
teraturako manual ezagunenetan ez datorrela idazle edo bertso berri jartzaile honen izenik. Santi Onaindiaren Euskal Literatura, bigarren alean, zehaztasuntxo hau aurkitu dugu «66 eta beste auek» atalean, 230. orrialdean: «Jean Etxepare, Done-Paule'ko semea, bertso berri mordoaren egillea». Uste dugu zehaztasun hori J. Bilbaoren bibliografiatik hartua dela. Ez dugu uste, kasu honetan behintzat, usteak albo ustela duenik. Baliteke, J. Etcheparek bertso berri mordoa egina izatea, baina guk, zoritxarrez, lau bertso-sailen berri bakarrik dugu.

Eta bere artikuluaren amaieran Kaltzakortak honako bertsoak ematen dizkigu: DOGA BURU-PIKATÇAILIAREN CANTU BERRIAC; CANTU DOLOROSAC 1888an emanac AINGERUEKIN DAGO; eta CANTU BERRIAC 1888an emanac CRIMA LAZGARRIA.

Jean Etchepare anitz bada euskal literaturan, bederen hiru ezagunak: apai$\mathrm{za}^{9}$, medikua eta saiogilea (1877-1935), zeinen obrari buruz Jean Casenavek tesi eder bat borobildu zuen ${ }^{10}$, eta gazterik hil zen ipuin idazlea $(1937-1961)^{11}$. Eta hemen aurkezten duguna laugarren idazlea litzateke.

Donapaleuko Udalaren agiri-liburuetan arakatzen aritu naiz, eta XIX. mendeko hiru Jean Etchepare ezberdin ateratzen zaizkit. Zein ote da bertsogilea? Bada bat 1852ko urtean klasatuak direnen artean, eta hogeiren bat urte izango zituena, baina 1832ko jaiotze-agirietan ez zaiguna agertzen. Eta beranduago jaiotako beste bi Jean Etchepare ere bai. Bat 1846ko maiatzaren 30ean jaioa, Catherine Etchepare 22 urteko neskaren semea, aita ezezaguna duena, eta bestea 1847ko urtarrilaren 14ean jaioa, aita-ama ezagunetarik.

Azken honen gurasoak Pierre Etchepare eta Marie Etchechoury dira. Aitak, beste askok bezala Ameriketako bidea hartu zuen, Argentinakoa hain zuzen, eta Montserrat-en hil zen, Buenos Airesetako probintzian. Jean Etchepare semea 1870ko urtarrilaren 17an ezkondu zen Marie Lataillade, Donapaleun (1844-III7) jaioa eta bera baino bi urte helduagoa zen andereñoarekin. Zehazki honela dio jaiotza agiriak:

L'an mil huit cent quarant-sept, le quatorze du mois de janvier à huit heures du matin, par devant nous Maire officier de l'état civil de la ville de St. Palais, canton de ce nom Département des Basses-Pyrénées; est comparu le Sieur Pierre Etchepare agé de vingt neuf ans, forgeron, domicilié à St. Palais, lequel nous a presenté un enfant du sexe masculin, né le treize du courant, à six heures du matin, dans la maison Murru de cette ville, de lui declarant et de Marie Etchechoury son épouse âgée de vingt six ans, et auquel il a declaré vouloir donner le prenom de Jean ${ }^{12}$.

Eta ezkontza errejistroak beste honakoa:

\footnotetext{
9 Tierceren escu-liburua, Baiona, E. Lasserre, 1862.

${ }^{10}$ Jon Casenave, 2002, De l'article de presse à l'essai littéraire, Buruchkak (1910) de Jean Etchepare. UNED ediciones, Madrid.

${ }_{11}$ Jean Etchepare, 1961, Mendekoste gereziak eta beste. Goiztiri.

${ }_{12}$ Donapaleu, Naissances. Registre Double 1847.
} 
L'an mil huit cent soixant-dix, le dix sept janvier, à neuf heures du soir, par devant nous Maire officier de l'état civil de la ville de St Palais, canton de ce nom, département de Basses-Pyrénées, sont comparus à la salle de la mairie, Jean Etchepare, âgé de ving trois ans, maçon, né à St Palais le quatorze janvier mil huit cents quarante sept, fils majeur de feu Pierre Etchepare, décèdé à Montserrat, province de Buenos Ayres le vingt sept avril mil huit cents soixante quatre, ainsi que cela résulte de son acte de décès produit et qui demeurera annéxé au présent, et de Marie Etchechoury, âge de quarante sept ans, journalière domicilié à St Palais, ici présente et consentante; et Marie Latallaide, âgé de vingt cinq ans, sans profession, née à St Palais le dix sept mars mil huit cent quarante quatre, y domiciliée, fille naturelle et majeure de Catherine Lataillade... ${ }^{13}$

Kontuak ateratzen baldin baditugu, hau Jean Etchepare koplaria balitz, 1847an Donapaleuko Murru etxean jaiotako primua, 1870ean Marie Latailladekin ezkondua eta Baionako hiriko heriotza agirietan ere Jean Etchepare bat ageri zaigunez 1898an hila, litzateke agian. Litekeena.

Bigarren Kantan dioenari jarraikitzen badiogu Gu Ameriketan soldado ihesi (II-11) Ameriketan ere egona litzateke soldaduskari ihes eginez baina ez dirudi oso oroitzapen onik ekartzen zionik bidaia horrek. Aita hilaren, Pierre balitz, gora beherak jakitera joana ote?

Pasaiako Udaletxeko agirietan ${ }^{14}$ bada 1854ean CHARLEMAGNE itsasuntzia Montevideorako hartu zutenen errolda, eta hemen 473 pasaiarien artean ageri zaizkigu bi Jean Etchepare. Bat Lukuztarra eta 17 urtekoa; eta bestea Baigorriarra eta 23 urtekoa bere anaiarekin doana, hirurak laborariak. Ez dirudi, beraz, gure Jean Etchepare, koplari donapaleutarra, baigorritar hau daitekeenik, izen bera eraman arren.

Bestalde, 47an jaioa maçon dela esaten zaigu, alegia hargin, eta Jean Etchepare bertsogileak sinatzen duen arabera, ancien boulanger ofizioz lehenik okin izan zen, beraz agian ez litzateke koplagilea bera, ez bazen bi ofizio horietan aritua bederen. Ikerketa, noski idekirik dago.

Geroago bertsotan ageri den ofizioa honakoa da; 1876 [...]. Etchepare, Jean. Rédacteur. Zein dira beraz, erredaktore honen lanak? Garbi dagoena da bertsopaperen jabego kontzientzia oso garbia zeukala eta hori azpimarratzen du behin eta berriro bertsoen bukaeretan modu zehatzez: Propriété réservé de Jean Etchepare. Tout contrefacteur sera poursuivi selon la rigueur des lois. [...] Tout contrefacteur ou colporteur sera poursuivi selon la rigueur des lois...[...] «vendu par les époux Etchepare».

Alegia bere jabego erreserbatua zirela bertso-paper haiek eta kopiatzen zuenari legearen zigor astuna gainean eroriko zitzaiola. Eta salmentan laguntzen zion emaztea Marie Lataillade ote zen? Auskalo!

\footnotetext{
${ }^{13}$ Donapaleu, Mariages. Registre Double 1870.

${ }^{14}$ Pasaiako Udaletxeko agirietan 1750-1, zenbakia duena.
} 


\section{Jean Etchepare koplariaren konplaintak}

Hona ondoren zerrenda, Jon Bilbaoren bibliografiatik eta Pariseko Liburutegi Nazionaletik harturik. Ematen ditugun urteak ez dira hala beharrez gertakizunaren urtea, saiatu baikara gaiei buruz mintzatzerakoan zertzelada horiek argitzen, bertso-paperaren urtearena baizik:

\section{Euskaraz}

1. 1873 [...] Complainta dolorosac Marseillaco Probentcian hamalau brigant italianouec egin dusten hamar Assassinamendu Crudelen gainian 1873 an emanac ${ }^{15}$.

2. $1876 \quad[\ldots] 226$ Passajers ithoric ${ }^{16}$.

3. 1876 Inondacione berrien gainian çombeit berçu berri guciec cantatceco emanac ${ }^{17}$.

4. $1876[\ldots]$ La Tombelle jaun baroinaren asasinamenduaren ganian ${ }^{18}$.

5. 1876 Accione crudelen gaineco, complainta dolorosac 1876an ema$n a c^{19}$.

6. 1882 [...] Marseillan içan den assassinamendu baten gainian cantu berriac $^{20}$.

${ }^{15}$ Cour d'Assises des Bouches-du-Rhône. Complainta dolorosac Marsellaco Probentcian hamalau brigant italianouec egin dusten hamar Assassinamendu crudelen gainian 1873 an emanac. Airia: Kriminelak bethi hatcemanac dira orotan. Orthez: J. Goude-Dumesnil, 1873.

Euskaltzaindiko liburutegia, Georges Lacomberen artxiboa, 554. zkia.

${ }^{16}$ Complainte sur l'épouvantable naufrage de «la Ville du Havre» Le navire français percé par le navire anglais 226 PASSAYERS ITHORIC. Lau Penduco Airia. Jean Etchepare. Pau: Impr. nouvelle, (1876).

Bibliothèque Nationale de France (Aurrerantzean BNF), YO-2 (Microfiche).

${ }^{17}$ Inondacione berrien gainian çombeit berçu berri guciec cantatceco emanac. Airia: Aita saldu nauzu idi bat bezala. Bayonne: impr. de C. Loustau, (1876).

BNF, YO- 1

${ }_{18}$ Arrêt rendu par la cour d' assises de la Haute-Garonne. Complainte sur l'Assassinat de M. le baron de La Tombelle, exécution de Mitron,âgé de 28 ans. et de Lasserre, âgé de 42 ans. Airia: Oura eta arnoua. Pau, Imp. Nouvelle, (1876).

BNF, YO-2 (Microfiche)

${ }^{19}$ Accione crudelen gaineco, complainta dolorosac 1876an emanac. Airia: Nahi gabe ainhitz da mundian guerthatcen. Bayonne: impr. de C. Loustau, (1876).

BNF, YO- 1.

${ }^{20}$ Cour d'Assises des Bouches-du-Rhône. (Aix-en-Provence). Marseillan içan den assassinamendu baten gainian cantu berriac. Airia: Cantatcera niaçu aleguera gabe. Dax, Imp. Nouvelle, 1882 .

BNF, RES ATLAS Z 52 (A,2,3). 
7. 1882 [...] Briganten yaureguia. Cantu berriac hamalau briganten eta hamaçaspi assassinamenduen gainian emanac ${ }^{21}$.

8. 1888 Cantu dolorosac 1888an emanac. Ä̈ngeruekin dago!22.

9. 1888 Cantu berriac 1888an emanac. Crima lazgarria! $!^{23}$.

10. 1889 Aphez pozoindatzalea ${ }^{24}$.

11. 1889 Botikario muthilaren asasinatzea ${ }^{25}$.

12. 1889 Aguer-Mizpirateguiren krima ${ }^{26}$.

13. 1889 Doga buru picatçailiaren cantu berriac ${ }^{27}$.

\section{Frantsesez}

1. 1876 Complainte sur l'assassinat de M. le baron de La TOMBELLE... ${ }^{28}$

2. 1876 Complainte sur les Crimes d'Aucamville... ${ }^{29}$

3. 1876 Complainte sur Le Crime de Lormont... ${ }^{30}$

${ }^{21}$ Cour d'assises de San Modina (Iles Philippines). Briganten jaureguia. Cantu berriac hamalau briganten eta hama-çaspi assassinamenduen ganian emanac.. Airea: Nahi gabe ainhitz da mundian guerthatcen. Dax: Impr. Nouvelle, 1882.

BNF, RES ATLAS Z 52 (A,2,3)

22 BNF, FCB, MS, n. ${ }^{\circ} 29$, f. 12.

Euskaltzaindiko Liburutegia. Lacomberen artxiboa, 554. zkia.

${ }^{23}$ Euskaltzaindiko Liburutegia. Lacomberen artxiboa, 554. zkia.

${ }^{24}$ BNF, Fol. WZ 700. Don Bibliothèque Mazarine 9476. Egileak Manech Etchepare bezala sinatzen du, eta 1894 zifra ageri da. Behar bada Anton Abbadiak Donibane Lohizunen erosi zuen Joanes Oxalderen bertsoarekin batera.

${ }^{25}$ BNF, Fol. WZ 700. Don Bibliothèque Mazarine 9476. Aurreko beste bi bertso-paperei buruzko gauza bera esan daiteke.

26 BNF, Fol. WZ 700. Don Bibliothèque Mazarine 9476. Egileak Manech Etchepare bezala sinatzen du, eta 1894 zifra ageri da. Behar bada Anton Abbadiak Donibanen Lohizunen erosi zuen Joanes Oxalderen bertsoarekin batera.

${ }_{27}$ Cour d'assises de Meurthe et Moselle, audiences des 28, 29, 30 novembre, 2, 3, et 4 décembre 1889. Condamnation à mort de Jean Dauga, le coupeur de têtes. [Complainte sur Dauga, par Jean Etchepare. Cour d'assises de la Gironde. Condamnation à mort d'Aguer dit le Basque, publiée par J. Etchepare. Complainte sur l'affaire Aguer par J. Etchepare. Cour d'assises de la Gironde. L'Empoisonneuse de Bordeaux.] Foix: Impr. de Gadrat aîné, (1889).

BNF, GR FOL LN16 14.

${ }^{28}$ Pau, Imp. Nouvelle, 1876.

BNF, 8 Fm 2148. YO-2

${ }^{29}$ Les Crimes d'Aucamville, près Toulouse. Exécution de Rieubernet. Suivi des détails de l'arrestation d'une bande de brigands. Bayonne: impr. de C. Loustau, 1876. Vendu par les Epoux Etchepare, Bayonne le 13 mars 1876. BNF 8 LK7 18843 (BISA).

${ }^{30}$ 1re partie. Cour d'assises de la Gironde. Crime de Lormont. Assassinat de Baptiste Méry, de Jonzac. Condamnations: de Juliette Garnier,... à perpétuité, Boucheau, dit le Manchot,... à perpé- 

4. 1876 Complainte sur l'exécution de Pascal... ${ }^{31}$
5. 1877 Le crime d'Agen. ${ }^{32}$
6. 1877 Complainte sur el crime de la Madrague ${ }^{33}$
7. 1882 Complainte sur le rapte de 18 jeunes filles ${ }^{34}$.
8. 1882 Une femme coupée en morceaux à Marseille 35
9. 1888 Une mère que decoupe son enfant.... ${ }^{36}$
10. 1888 Les mères criminelles ${ }^{37}$.
11. 1889 Complainte sur Dauga ${ }^{38}$
12. 1889 Complainte sur Aguer ${ }^{39}$

Gehiago idatzi ote zituen Jean Etchepare donapaleutarrak? Dudarik gabe, bai, beraxek esaten baitigu Briganten jauregia... titulua daraman bertsoaren amaieran honakoa: ... Complainte sur le rapte de 18 jeunes filles. Parisen laü urtheco haur bat içan da berrogoi eta hirur pusketan eçarriric. Courrier bat assassinaturik. Eman dugu heyen cantuac, cembeit egunen burian ASCAINECOAC ERE.

Eta, beraz badago ikerketa lana oraindik. Aurkitu ahal izan ditugunak hamahiru dira eta honela Kaltzakortak bildu hiru kantei beste hamar erantsi ahal izan diegu, aski interesgarriak direnak gure ustez, eta ondoren aztertu eta emango ditugunak.

tuité, Jean Pascal,... à la peine de mort !!! [Air de Fualdès. Complainte véridique sur le crime de Lormont... Signé: Jean Etchepare. 2e partie. Exécution de Pascal le lundi 3 Juillet,... à Bordeaux. Avec les plaidoiries. Complainte sur l' exécution de Pascal... Signé: Jean Etchepare.]. Pau: impr. A. Menetière, [1876].

BNF. 4 FM 34691

31 Idem: BNF4 FM 34691

${ }^{32}$ Cour d'assises de Lot-et-Garonne. Audience du 4 Septembre... le crime d'Agen. Parricide. Condamnation à mort. Chant lugubre et moral sur le crime d'Agen. Signé: Jean Etchepare Pau: impr. A. Menetière, 1877.

BNF4 FM 17996 [ doc. non communicable] (1877).

33 Complainte sur le crime de la Madrague. Air: Mongaillard Eugène. Pau, Impr. Nouvelle,

\section{BNF $\quad 4 F M 2849$}

${ }^{34}$ Euskaltzaindiko Liburutegia . George Lacomberen artxiboa, bertso paperak, 554. zkia.

35 Euskaltzaindiko Liburutegia . George Lacomberen artxiboa, bertso paperak, 554. zkia.

${ }^{36}$ Euskaltzaindiko Liburutegia . George Lacomberen artxiboa, bertso paperak, 554. zkia.

${ }^{37}$ Euskaltzaindiko Liburutegia . George Lacomberen artxiboa, bertso paperak, 554. zkia.

${ }^{38}$ BNF. GR FOL LN 1614.

${ }^{39}$ BNF GR FOL LN 16-14. 


\section{Konplainten gaiak}

Bi motako gaiak ditu tratatzen Etxeparek bere kantuetan: krimenak eta zorigaitz naturalak, hala nola itsasuntzien ondoratzeak eta uholdeak. Azken hauek aurkezten hasiko gara lehenik.

Esan bezala badira bi kantu ezberdin naturak eragin zorigaitzen gainean, hau da, bat 1873an gertatu Ville du Havre-ren hondoratzea kontatzen diguna, lainoek eragina, non 226 pasajers ithorik bukatu zituzten beren egunak, eta bestea 1875 eko inondazioneak, uholde izugarriak aipatzen dituena.

VILLE DU HAVRE itsasuntzia Ingalaterran eraiki zen eta Compagnie Général Transatlantique deituak eginarazitako azken pakebote gurpilduna izan zen. Le Havre-tik New-Yorkerako itsas bidaia egiten hasi zen 1866an NAPOLEON III-a izenez, baina 1871-72an berregin zuten hamazazpi metroz luzatuz, helizez hornituz, eta bi masta ordez hiru eraikiz. Eta beste izenez bataiatu zuten, hots, VILLE DU HAVRE gisara, zerbitzuari 1873ko martxoaren 3an heldu ziolarik. Urte honetako (1873) ekainaren 6an, CURAÇAO hiru mastadun itsasuntziarekin topo egin eta hondoratu zuen Hudsongo badian. Azaroaren 16an uzten du Le Havre 313 pasaiariekin eta gau beltzean LOCH EARN hiru mastadun angelesak hondoratzen du, zeina 12 minuturen buruan gertatu zen. Bakarrik 61 pasaiari eta ekipaiako 26 salbatu ziren, TREMOUNTAIN itsasuntziak bilduta eta azkenean Bristolgo portura arribatuz. Bere aldetik LOCH EARN hurrengo urtean azaroaren 18an hondoratu $\mathrm{zen}^{40}$. Ixtorio triste hauen aintzidaritzat jo ditzakegu adibidez ZARRANTZA ${ }^{41}$ eta PULUNPA ${ }^{42}$ euskal poemak, beste bi hondoratzez idatziak.

Hemen emigrazioaren, hau da, ameriketaratzearen aurka ere mintzatzen zaigu, berak ezagutu baitzuen egoera, soldadoxkatik ihesi joan zelako. Baina dioenez, bakoitzak bere sorterrian, jaiotako lurrean bilatu beharko luke bere bizitza.

Maiz gertatzen ziren horrelako ondoratze eta uholdeak eta adibidez urte batzuk geroxeago 1882ko urriaren 29an Bretaña aldean ekaitzak bortizki jo zuen eta ondorio gaitzak erakarri. Ondorioz Dieppe-n azaroaren 4ean koplariak bertso-paperak saldu zituen hamar zentimotan, en profit des familles des naufragés, hots, hilen familien alde ahaleginduz bere kanten bidez sos batzuk biltzen.

Bestalde 1875EKO INONDAZIONEAK ikaragarriak izan ziren ere. Frantziako Tolosan bertan 1219 etxe desegin baitzituen ekaitzak ${ }^{43}$, — kantak zazpiehun etxe, dio - eta gutxienez 218 mila hil eragin. Gaur egun oraindik Aturri ibaiako zubian seinalaturik dago Bagnères-de-Bigorre-tik igarotzean harroin batean, crue du 23 juin 1875, alegia 1875eko ekainaren 23an honaino igo ziren ibaiako urak. Hona nola ikusten duen Etcheparek kantaren 9.bertsoan:

\footnotetext{
40 www.frenchlines.com

${ }^{41}$ Patri Urkizu, Bertso zahar eta berri zenbaiten bilduma (1798). Durango, 1987, 102-105.

${ }^{42}$ Francisque Michel, Le Pays Basque, 1857, 348-352. Basa nafartarra, PULUNPA deitura duen bertsoa eta $1842 \mathrm{ko}$ ixtorioa kontatzen duena da.

${ }^{43}$ www.jacobins.mairie.toulouse..fr
} 
Aita amak nigarrez haur gaixuen ondotik,

Heiagora, marraskaz, teilatu gainetik,

Abertimendu hori jautsi da zerutik,

Nigar egin dezagun holakoen gatik. (III-9)

Dena den, hilketa bortitzak, asasinamenduak izanen dira bildu ahal izan dugun euskarazko corpus-eko kantu gehienak, hots, hamahirutik hamaika. Eta zergatik hori? Aipatu dugu sarreran jenero beltz honen, edo urkamendiko bertsoen eta ixtorioen arrakasta handia dela medio, mende anitzetan zehar eta batipat XIX. mendeko bigarren partean. Etcheparek berak ere, besteak beste, honakoa dio bere frantses complainte baten aitzin solasean:

[...] À toutes les époques de la vie on a dû enregistrer les actes célèbres et criminelles qui ont eu un grand retentissement et une bien triste célébrité; mais que sont après tout ces grands scélérats, qui ont chacun à leur tour préoccupé l'opinion publique. Que son les Brinvilliers ${ }^{44}$, les Lavoisinn ${ }^{45}$, les Cartouche ${ }^{46}$, les Mandrin ${ }^{47}$, les Latour ${ }^{48}$, les Troppmann ${ }^{49}$ à comparer aux deux scélerats, dont aujourd'hui nous faisons le sujet de notre narration? Rien, ou presque rien, car...50

Mota honetako pertsonaiak aipatzen ditu ere Pio Barojak ${ }^{51}$, honelako ixtorio izugarrien oso zalea baitzen, Parisen funtzionatu zuen gilotinaz mintzatzerakoan ere artikulu batean.

${ }^{44}$ Marguerite d'Aubrai, Brinvilliers-ko markesa 1676an akusatua izan zen anitz pertsona pozoinez hiltzeagatik. Epaitu eta kondenatu ondoren, uztailaren 16an erre zuten. Kanta ezagun bat sortu zuten bere oroitzapenean «Puisqu'il me faut mourir» titulua emanez. (France Vernillat \& Pierre Barbier, Histoire de France par les chansons. Paris: Ed. Max Fourny 1982, 69.)

${ }^{45}$ Catherine Deshayes «La Vosin» (1640-1689), beste pozointzale frantses ospetsua.

${ }^{46}$ Cartouche, Louis-Dominique Bourguignon (Paris 1693 1721). Bandido famatua, bere sarraskiak Pariseko inguruan burutu zituen. Hil zuten egunean jada bertso eta liburu saltzaileak haren bizitza eta heriotzari buruzko erretratu eta kantak saltzen zituzten. (Histoire de la vie et du procès du fameux Louis-Dominique Cartouche. Troyes: Chez Baudot 1722). Ba omen zen Chahoren iritziz pastoral bat haren bizitzaz moldatua ere.

${ }^{47}$ Louis Mandrin (Saint-Etienne Geoirs Valence 1755). Kontrabandista eta hiltzaile ospetsua. Yves Montand-ek kantatzen du honi buruzko konplainta.

${ }_{48}$ Jacques Latour, Senteinen jaioa, 1864ean Baillard de Bugad de Lassalle-ko gazteluan lau hilketen ondorioz preso hartu zuten eta kartzelatik ihes egiten saiatzeagatik, Foixen gilotinatu zuten.

49 Jean Baptiste Troppmann (1848 1870). Hiltzaile ospetsua. Honi buruz Justo irundarrak 26 bertsoko ixtorioa asmatu zuen: Verso berriac irundar batec jarriac (BNF. FCB, n. ${ }^{\circ}$ 169, f. 371).

${ }^{50}$ Jean Etchepare, Le crime d'Empouillac. Assassinat de M. le Baron de la Tombelle... Pau, Imprimerie Veronese. Sd. BNF, 8Fm 2148.

51 «Hablo de Lacenaire, Papavoine, Tropmann, Lelier y Barre, Marchandou, Pransini, Prado y Landru. Les cuento cómo Lacenaire hacía versos...», José-Carlos Mainer (ed.), 1999, «La guillotina en París», Pio Baroja. Obra dispersa y epistolaria. Obras completas, XVI. Barcelona: Círculo de lectores, 1351-1356. 
Hiltzaile mota ezberdinak dira, dena dela, ageri direnak kantu hauetan. Isabel Segurak gaztelaniaz Romances Horrorosos ${ }^{52}$ izenpean aurkeztu zuen bilduman honela sailkatu zituen zergatikakoak: a) Lapurretak, b) Pasioak eraginak, c) Perbertsioarenak, eta d) Politikazkoak.

Julio Caro Barojak badu bere aldetik entseiu gogoangarri bat ${ }^{53}$ gaiarekin lotua, eta bilduma bat Romances de ciego izenpean ${ }^{54}$. Titulu honen arrazoia da Espainian erromantzeak eta liburu merkeak hedatu zituztenak itsuak zirelako. Hauek prototipo bat osatu dute literaturan Tormesko Lazarilloaz geroztik. XVIII. mendean Madrideko Itsuen Anaitasunak bazeukan pribilegio bat, zeinen arabera heriotze zigorra pairatu behar zutenen ixtorio labur bat jasotzen zuten Justizia Jauregitik, zeina beren elkartekoen artean banatzen zuten, hauek gogoko bazuten beren erromantzeak sor eta sal zitzaten.

Lapurren historia munduan barrena luzea da eta ia kontaezina. Euskal Herriko lapur eta bandidoena ere ez da tipia. Duela gutxi Xabier Martinek. «Bide lapurrak Euskal Herrian» izeneko artikuluan ${ }^{55}$, aipatzen zigun David Zapirain historialariak euskal bandidoei buruz moldatu liburuan ${ }^{56}$ ageri direnen izenak eta balentriak.

Jadanik XII, mendean Aymeric Picaud-ek idatzi zuenean bere Codex Calixtinus delakoa edota Santiago bideko gida, pelegriek Euskal Herritik igarotzerakoan aurkitzen omen zituzten zenbait. Hona dioena ${ }^{57}$ :

En territorio todavía de los Vascos, el Camino de Santiago pasa por un monte muy alto, denominado Port de Cize, bien por ser la puerta de España». o porque por ese monte se transportan las mercancías de un país a otro. Tiene ocho millas de subida y ocho de bajada: [...]

En ese monte, antes de que el cristianismo se extendiese por todo el territorio español, los impíos de los navarros y de los vascos, tenían por costumbre, a los peregrinos que se dirigían a Santiago, no sólo asaltarlos, sino montarlos como asnos y matarlos.

XIII. mendeko kronikek dioskutenez, garai haietan ere ugariak ziren baserritarren arteko abere lapurketak, ahuntzenak, zaldienak, behienak eta beste, Burunda Aldean, adibidez. Bardeetan barrena ospetsua izan omen zen XV. mendean Santxiko Rota delako bat.

Lapurreta mota anitz bada, dakigunez, eta hauen ondorioz gertaturiko hilketak ugariak. Lapur mota berezi bat osatzen dute ordea, lapur onak, edo ban-

52 Isabel Segura (ed.), 1984, Romances horrorosos. Selección de romances de ciego que dan cuenta de crímenes verídicos, atrocidades y otras miserias humanas. Barcelona: Alta fulla, ix. dente.

${ }_{53}$ Julio Caro Baroja, 1969, Ensayo sobre la literatura de cordel. Madrid: Revista de Occi-

54 Julio Caro Baroja (ed.), 1996, Romances de ciego. Madrid: Taurus.

${ }^{55}$ Berria, 1009ko azaroaren 20 a.

56 David Zapirain, 2009, Bandoleros vascos. Tarttalo.

57 Millán Bravo Millán (ed.), Guía del peregrino medieval (·Codex Calixtinus»). Centro de Estudios Camino de Santiago. Sahagún 1991, 34-35- 
dido onak. Famatuen artean ditugu Robin Hood edo Ivanhoe, aberatsei kendu eta pobreen artean banatzen zituztenak.

Horietarikoa zen ere, antza denez, Juan Antonio Madariaga «Patakon» galdakaoarra (1796-...), zeini buruz esaten zen errefrau ezagun hura: Patakon dekoneri kendu eta eztekonari emon.

Zenbait mende geroago Txitxo Baztango bandoleroa ere famatua egin zen, Elsoko apaiza izanda gero, sotana zintzilikatu eta aberatsei kentzen ziena pobreei emateko.

Errefrau zaharretan ere ageri zaizkigu ohoin eta urkatuez moldaturikoak. Hala, Igazko lapurrok aurtengoen urkatzaila (RS, 96); Urkatu baten hobian ehun gaxtagin ehorzten dira (Oihenart, 459), alegia gaxtagin baten urkatzeak beste ehun zuhurtzen dituela, edota Ohoin handiak urkaerazten ditu xipiak (Oihenart, 657).

Ez zaigu ageri bilduman horrelakorik. Lorrenako eta San Modinako brigantak, hiltzaileak, adibidez, bihotz gogorrak ziren, baina hilketaren zio nagusia diru lapurreta izan zutenak.

1841eko otsailaren 2an Brichquet famatua heriotzez zigortu zutenean Donapaleun, jende multzo handi batek ikusi zuen bere bizitza guztirako markaturik gelditu zelarik. Brixket delakoa Jean Elichalt zen deituraz, M. Larrazain Domenzainekoa hil zuena eta Pabeko asisetan 1840. azaroaren 19an kondenatu zutena heriotze zigorrera. Jean Etchecoinek ${ }^{58}$ argitzen digunez, jende multzo handia bildu zen haren gilotinatzea ikusteko eta hiltzailea maradikatzeko, baina nola gertatzen zen ikusiz, jendeari oihu egiteko gogoa joan omen zitzaion eta begietarik malkoak isuriarazten omen zizkion.

Konplainta bat idatzi zen ere gaiaz frantsesez faksimilean emango duguna amaieran $^{59}$.

Hona nola jaso zuen Sentinelle des Pyrénées, Baionako egunkariak albistea 1841eko apirilaren batean:

Vendredi dernier, une foule immense encombrait les rues de Saint Palais. Depuis vingt ans et plus, la population du pays n'avait eu le spectacle d'une execution capitale, et celle qui allait avoir lieu lui promettait des emotions inconnues ou oubliées. Elichalt, l'assassin de Domezain, devait expier par la mort le crime d'avoir donné la mort. L'absurde et atroce loi du talion lui avait été appliquée. D'après les détails que nous avons recueillis sur les derniers moments de ce malheureux, il a dû contenter pleinement la curiosité des nombreuses spectateurs du drame dans lequel il jouait un si triste rôle. Elichalt se présente escorté de huit gendarmes et assisté par deux ecclésiastiques. C'est un

58 Jean Etchecoin, 1933, «La prison de Saint-Palais», Bulletin de la société des sciences, lettres et arts de Bayonne, 353.

${ }^{59}$ Complaint sur l'assassinat de M. Larrandart de Domezain. Orthez, Imp. Dumesnil et Arborin, s.d.

BNF, 8 - FM - 1067. 
bel homme, dans toute la force de l'âge; on a peine en le voyant à comprendre le crime qui l'a fait condamner. On se demande comment un homme en qui tout décèle le courage et la force, qui devait trouver facilement dans son travail d'honorables moyens d'existence, s'est laissé entrainer par l'appât de quelques pièces d'argent, à l'assassinat d'un vieillard octogenaire.

En fin le moment fatal est arrivé. Au pied de l'echafaud, Elichalt se met à genoux et fait une dernière confession; puis, il monte d'un pas ferme les degrès qu'il ne doit point descendre vivant. Pendant que l'executeur faisait les derniers preparatifs avec une emotion dont le courageux patient s'aperçut: Tu trembles, -lui dit Elichalt en jetant un regard assure sur le fatal couteau-, moi je ne tremble pas ${ }^{60}$.

Baliteke etxean behin baino gehiagotan ixtorio hau entzuna izatea edo bertso papera irakurria izatea eta bere bizitzarako markaturik gelditzea Etxepare.

Hamalau brigant italianoez mintzatzen zaigun kanta dugu denboran lehena, $1873 \mathrm{ko}$ baita. Bertan Lataille-ren banda deitzen zen bandido multzoak Marseillako probintzian burutu zituzten hilketak eta lapurretak salatzen ditu. Hona hemen xehetasun batzuk. 1871eko maiatzaren 15ean Mallemort-en Martin Durance-ko guardia hil zuten. Abuztuaren 19an Bastidonne inguruan Oscar Loneux ganibetaz zauritu zuten erlojua, arropak eta poltsa lapurtzearren. Irailaren 2tik 3ra ganibetez André Garnier, Veronique Garnier, honen alaba Euphrasie, Sube anderea, Rosa iloba, Alpeetako Lurs-eko etxaldean. Urriaren 25ean Elgeard Sautel 44 urteko mezulariari burua hautsi zioten, eta 1871eko azaroaren 4ean Mayrargues-en Lambot alarguna 76 urtekoa asasinatu zuten. Jacques Ribetto bandako partaideak hildakoaren ongiak erosi zituen eta polizia atzetik jarri, eta azkenik detenitu ondoren bere kide guztiak salatu zituen. Batzuek betiko galeretara kondenatu zituzten eta bai Galetto eta bai Gabarino gilotinara.

Ama kriminelez edota infantizidioez baditu Etcheparek bi kanta ondurik (VIII, IX). Anicck Tillier-ek ${ }^{61}$ esaten digunez, ez ziren salbuespen jaioberrien hilketak. Ezkongabe, monja, adulteriogile edota alarguntsak anitz ziren gizartearen gaitzespena sufritu aitzin beren erraietako fruituak akabatzen zituztenak, eta ondorioz askotan salatuak zirenean epaitegira eramanak eta batzuetan gilotinatuak ere izaten zirenak.

Ama eta aita haur hiltzaileak, alegia infantizidak direnean, edota ama bere alabaz asasinaturik (VI-5b) gertatzen denean ixtorian, krima benetan perbertsoak, naturaren kontrakoak kontatzen dituzte...

Ama alabak hila dugun kasuan, hala nola Leon-Paul Vitalis eta Maria Boyer-ek eraginean honela laburzki gertatu omen zen. Vitalis liburu saltzaileak

${ }^{60}$ SENTINELLE DES PYRÉNÉES, n. ${ }^{\circ}$ 1508, Bayonne, 1-IV-1841.

${ }^{61}$ «Au XIXe siècle, les meurtres de nouveau-nés ne sont pas exceptionnels. Célibataires, adultères ou veuves, des milliers de femmes ont été jugées pour ce crime en France. Les archives judiciaires permettent de cerner au plus près les circonstances de leur acte.» Annick Tillier, 2003, «Infanticide: le procès des mères criminelles», L'HISTOIRE, n. ${ }^{\circ}$ 282-12. 
Maria Boyer bere andregaiaren laguntzaz 1877ko martxoaren 19an Marseillako hirian ostiral batez goizeko lauak eta hiru ordu laurdenetan Marie Salat, Boyer alarguntsa, gozoki eta mertxeria denda baten jabe zena hil zuten, zatikatu eta gorde, baina gorpu laurdenkatua agertu zenean presondegira eraman zituzten. Kartzelako kaperan Bessac apaizak meza eman zuen, Vitalisek eskatu zuen berak laguntzea, baina ukatu egin zitzaion. Urkamendira igo zenean Sébastopol plazan, belaunikaturik, uxerrak heriotze epaia irakurri zion eta Garnier apaizak barkamena eman. $1877 \mathrm{ko}$ uztailaren 5 a zen ${ }^{62}$. Noski, frantsesez ere konplaintarik merezi izan zuten ${ }^{63}$.

La Tombelle baroinaren hilketa 1873ko urriaren 16an gertatu zen bere Ampouillac-eko jauregian, Cintegabelle-n. Pierre Lasserre eta Philippe Mitron Le Vaineur zerbitzariak, lapurreta helburu, izan ziren hiltzaileak eta jauregiari su eman ziotenak. Poliziak Lasserrerena zen zurgin metro bati jarraiki jakin zuen nor ziren hiltzaileak. Heriotze eguna iritsi zenean, 1874eko martxoaren 5ean, Levaineur lasai dago eta ardoa eskatzen du saltxitxoia bustitzeko; Laserrek, aldiz, oso urduri, ezin du hitzik atera. «Mitron»-ek eskaintzen zaion gurutzea besarkatzen du, aldamenean Pelletan apaiza eta Nicolas Roch burregoa dituela, lanturik gabe doa. Lasserre oihuka hasten da, Mon Dieu Seigneur! Gilotina akats batez biderdian gelditzen da, baina konpontzen dute eta berehala hiltzailearen izu marrasken artean honen lepora erortzen da eta mozten burua.

Ixtorio honen xehetasun gehiago irakurle zaleak aurki ditzake Armand Praviel-ek 1936an idatzitako lanean La Revue Belge- $\mathrm{n}^{64}$.

Filipinetako hamalau brigantei buruz eta hamazazpi asasinamenduen gainean egin kantari buruz ez dugu albisterik batere ediren. Filipinetako San-Modin irla eta hiriaz, Pedro Bendarez eta Stephano Diaz brigante izugarriez, Jose Pozzol aita errukigarriaz, hamazazpi neskatxen hiltzaileez, deusez. Balirudike zazpi mila uharteetan galdurik gaudela. Beraz euskarazko kantarekin konformatu beharko bakarrik. Bertso-papera Akizen 1882an agertu zenez gertakizunak aitzinakoak ziratekeen, noski.

Aphez pozoindatzalea bezalako ixtoriarik gutxi aurkituko dugu euskal literaturan. Honi buruz Lionel Dumarcet-ek idatzi du liburu aski interesgarri eta ongi dokumentatua, berriki argitaratu dena ${ }^{65}$, zeinak adierazten duen oraindik honelako aferak sortzen dutela interesik.

Bertan ikus dezakegu nola Joseph Auriol, hogeita zortzi urteko apaiz gaztea Ekialdeko Pirineoetako Nohèdes-eko herrixkan, maitemintzen den Alexandrine Vernet maistrarekin, eta nola ihesi elkarrekin egin baino lehen lapurtzen eta pozointzen dituen berarekin bizi ziren Maria eta Rosa Fonda ahizpak 1881. urtean.

\footnotetext{
${ }^{62} \mathrm{Htttp}$ //guillotine.site.voila.fr/Palmares1871-1977.

${ }^{63}$ Complainte de Vitalis et Maria Boyer. Une femme coupée en morceaux. Assassinat et parricide. Marseille. Imp. Bernas 1877. BNF, YE -7183.

${ }^{64}$ Arnaud Praviel, 1936, «La mort misterieuse du Baron de la Tombelle», LA REVUE BELGE, 289-323.

${ }^{65}$ Lionel Dumarcet, 2006, Grands Procès. L'Affaire Abbé Auriol. Les faits, les protagonistes, l'enquête, le procès, les rebondissements et les nouvelles hypothèses. Paris: De Vecchi.
} 
Izugarrizko eskandala sortu zen, noski, garaian, eta betiko galeretara kondenatua izan zen.

Bertso paperean, ilustrazioetan ikusiko dugunez, apaizaren irudia ageri zaigu, La Tombelleren hilketa bertsoan bezalaxe.

Hiltzaileetarik bat badugu euskalduna dena, Jean Aguer Mizpirateguy, dit le Basque. Likin jaioa, Zuberoako partean, soldadutza egin eta etxera itzuli zenean badirudi, antza, ez zuela aurkitu oso harrera onik. Ondoren badoa beste hainbeste gisa deserrira bizimodua aurkitzera. Bordelen su-hiltzaile lanetan arituko da, bai eta portuko kaietan zamaketari. Ez dirudi beste kriminalen gisa, berezko gaiztakeriarik zeukanik Agerrek, koplariak toki guzietan Aguer konportatu da oneski baitio.

Baina emaztegai gaixoa, Juliette Andrieux, haur esperantzetan utziko du eta tronpatu eta gero hil eginen du, diru puxka batengatik, antza.Gorpua gorde ondoren badoa ihesi Espainia aldera. Poliziak Landetan aurkituko du, kartzelara eraman eta asisetan kondenatua izango da. Carnot presidente frantsesak, —urte batzuek geroago 1894eko ekainaren 25ean Caserio anarkistak hil, eta zeinaren gainean Oxaldek bertsoak moldatu zituen ${ }^{66}$ - heriotze zigorra barkatuko dio, eta 29 urtez Caledonia aldean desterraturik galeretan bizi behar izango du.

Le crime de Pecq ${ }^{67}$, edota Luis Aubert botikari mutilaren hiltzea aurkeztuko dugu, hots, Fenayrou senar-emazteen afera, non oso ospetsua izan zen ${ }^{68}$ hilketa burges baten aitzinean aurkitzen garen. Marin Fenayrou botikarioa aspalditik tronpatzen du bere andere Gabriellek botikako mutikoa den Louis Albert-ekin. Hau Seine ibaian aurkituko dute itoa, berunezko hodi bati atxikia, ahoa andere orratz batez josia eta zango-besoak sokaz loturik.

Adrien C. Ritchie, Galles-eko herrialdeko Unibertsitatean irakasle denak, hilketa honen inguruan Mirbeau eta Maupassant-ek idatzitako kronikak aztertzen ditu' ${ }^{69}$ Maupassante-k honela hasten du artikulu bat: Quel enseignement pour les romanciers que ce fameux drame du Pecq?

Zeren ez baita senar adardun baten mendekio hutsa ixtorioa, guztiz arrunta litzatekeena. Barre egiten du ohiko kazetariez, eta afera desdramatizatu egin nahi $\mathrm{du}$, egiaren gertuago izatearen ahaleginean, eta ondorio honetara iritsi, alegia, Gabrielle est tout simplement une femme pareille à beaucoup d'autres. Beste hamaika andere bezalakoxea dela.

66 Joanes Oxalde, «CARNOT PRESIDENTAREN HERIOTZEA EKHAINAREN 24AN 1894AN. «Bayonne, Imprimerie Lamaignère, rue Jacques Lafitte, 9. «acheté à Saint-Jean de Luz le 28 7bre 1894» (Anton Abbadiaren hitzak eskuz idatziak). BNF, Recueil de pièces de poésie basque. Z-71.

${ }^{67}$ André Camps, «Le crime du Pecq», Gazette Agricole, Paris, 1882-VI-18;

68 Albert Bataille, 1882, «Affaire Fenayrou», Causes criminelles et mondaines. Paris: E. Dentu, 206-292.

69 Adrian C. Ritchie, «Mirbeau et Maupassant: Deux chroniques sur «Le crime du Pecq» (1882)». Cahiers Octave Mirbeau, n²13, mars 2006, 195-196. 
Mirbeau-k, aldiz, bere umore beltzaren adierazteko erabiliko du gaia, eta bidenabar Epaileen sistemak dauzkan kontraesanak salatzeko. Biak, dena den, bakoitzak bere erara baliatuko dira prentsaren bitartez eta gertakizun arrunt batez ariketak egiteko eta ondoren beren lan literarioetan murgiltzeko. Halaber Jean Etcheparek moral ikaskizuna ez du ahanzten:

Senharra gilotinatu, andrie galeretan,

Oihu egiten zuten bainan alferretan,

Heiagora marraska bazen karriketan,

Gaztigu ederra da andre ezkonduetan. (XI, 10)

Baina ez ziren benetan besteen kasuetan bezain tragikoak izan ondorioak Fenayroutarrentzat. Kausaren berrikuspenaren ondoren, forma akatsak zirela eta, Marin ez zen gilotinatua izan Nouvelle-Caledonie-ra eraman baitzuten, eta Gabrielle Clermont-eko Etxe nagusian (Oise) zaindua izan zen.

Eta bukatzeko Jean Dauga buru pikatzailearen bizitza Etcheparek bertsotan eta hitz lauz ematen diguna aurkeztuko dugu. Hau zertxobait osatu eta zuzenduko ditugu.

Dauga, Cazaubu (Gers) ondoko herri txiki batean jaio zen, — Larée-n, hain zuzen, bertsoak besterik dioen arren - . Gazterik hasi zen jende hiltzen, zeren 1869an jadanik bere lagun errotazain bat hil omen zuen Larée-ko eiheran.

Soldaduska burututakoan Vosges aldean kokatu zen jendarma gisa. Itzultzen da Gers-era 1881ean, eta hantxe Courrèges alarguntsa mailukadaz hiltzen du. Gers-eko asisak frogarik ezean libre uzten du (1881-X-28). Vosges-era itzuli eta inprimatzaile lanetan hasten da, eta etengabe jende hiltzen.

Hala Pernod senar-emazteak, Martin senar-emazte tapizegileak Sant-Nabord-en 1888ko martxoaren 15ean, Sulzer senaz-emazte oihalgileak 1888ko azaroaren 18an, Ferry anderea 1889ko otsailaren 5ean eta François alarguna handik bi egunera.

Azkenik preso hartu zuten, juzkatu eta gilotinara kondenatu. Antza denez, berak beti ukatu arren eta berarekin injustizia egiten zela aldarrikatu, maiz ibiltzen zen putetxeetan eta jokoan xahutzen ohozturiko diruak, diru lapurreta izan zelarik hilketen arrazoia.

Heriotze zigorra egunean 6.55etan jaiki, lasai jantzi, zigarrotxo bat erre, kafe beltza ron ttanttaz bustia, eta lasaiki emazteari idatzi zion. Aitortu, barkazioa lortu eta komunioa ere hartu ondoren zigorra eman zioten. Ia bakarrik hil zuten, ordea, jendetza, bi mila pertsona inguru beste leku batean bildurik baitzegoen, hau da Hegoaldeko hilerrian ${ }^{70}$.

Gertakizun honetaz oihartzun ere egin zen Eskalduna, Baionako astekaria, honela komentatuz Petite chronique atalaren azpian:

${ }^{70}$ http: // site. Voila.fr/guillotine... 
Krimaric izigarrienac noiz nahi eginac dira Frantzian. Dauga deitzen den kriminel handi bat hiltzera kondenatua izan da aste huntan; laur presuna bazituen asasinaturic berrikitan eta lehenago ere uste dute bazuen bertze zonbait hilic. Haren prosesean yendea saldoka ibili da eta izigarri muntatua izan da asasinazalearen kontra. Presondegirat ereman dutenean populuac laurdengatu nahi zuen; lanac ukhan dituzte yandarmec gizon trichte haren zaintzen $^{71}$.

Frantsesez idatzien artean hor daukagu besteen artean François Rieubernet, bere ama Mme Laval-en hiltzailearena edo eta Jean Baptiste Pascal-ena.

Lehenak 1874eko azaroan asesinatu nahi izan zuen Bordes jauna Bruguièresen, eta 1875 eko otsailaren 1ean Eugène Sins hil zuen eta honen emaztea bortizki zauritu Aucamville-n.

Mac-Mahonek graziatu nahi izan zuen, baina egun batzuk aitzin, presozainari lepoa trenkatzen saiatzeagatik, azkenean, Port-Garaud-en Pelletan abadea lagun, goizeko lauak eta hiru ordu laurdenetan 1875eko maiatzaren 19an uztailaren 13 an gilotinatu zuten Tolosan.

Bigarrenak Lormont-en krima burutu zuen, alegia, Baptiste Méry serrailagilea hil zuen 1875eko urrilaren 29an, lapurreta helburu. Engainaturik Pascal bere amoranteaz, Juliette Garnierrez harrapatua izango da hala nola beste konplizea, Bouchau «Manchot» deitua, betirako galeretan kondenatuak izan ziren. Bordelen, Place du Repos-en, Pascalek apaiza eta borrero besarkatzen ditu eta 25.000 pertsonen aurrean gilotinatu zuten 1876ko maiatzaren 13an.

\section{Hizkuntza eta estiloa}

Jean Etchepare Donapaleukoa denez, ez dago dudarik behenafarrera dela darabilen euskalkia. Adibidez, dagozkion hasperentasuna (-h-) eta monoptongazioak (ai > i; au > u...) mantentzen ditu, hala nola: hasi niz erraten (III-10); $n i$ ere hilen nu (IX-10); haren xerbutxuak gitu estonatzen (XII-3) ...

Halaber, hitz mailegu ugari ageri zaizkigu, idazle eta kantari herrikoia zenez eta ez apaiz kultoa. Adibidez: akzione, asasinatu, asisa, beztitu, briganta, desordre, frauda, frontera, galerano, gara, gilotina, kantore, konplainta, krima, krudel, kuerda, mala, prefeta, preso, puñal, xefa, ...

Jakina da, dena den, hitz zenbaitek bide luzea egiten dutela hizkuntza batean txertatu arte.

Adibidez, darabiltzan asasinatu, asasinamendu, asasinatzale hitza arabetik dator, hots, hachchachi-tik, esan nahi da, haxisa edaten duena, hots, kainamo ostoz egin edari narkotikoa, zein Mendiko Zaharraren jarraitzaileek XI. mendean edaten zuten mendekio odoltsu eta hilketak burutzearren. Hitz hau gero italianora eta frantsesera ondoren iragan zen.

\footnotetext{
${ }^{71}$ Eskualduna, Baiona, 1889-XII-6.
} 
Asisa, hitza, ezaguna den bezala frantsesetik dator, non Cour d'assises sintagma bezala erabiltzen den adierazteko epaitegi kriminala, magistratu eta epailez konposatua, kriminalak eta hobendunak juzkatzeko.

Briganta hitza ere frantsesetik dator, zeinak era berean italianoan duen etorkia: brigand $\mathrm{fr} .<$ brigante it. , gaizkile esanahi du.

Gilotina hitza Iraultza frantsesan modan jarri zen, hots, 1789az geroztik, eta bere asmatzailea edo hobeto esan erabileraren proposatzailea izan zen Joseph Ignace Guillotin. Mediku eta diputatu honi zor zaio beraz erabilera, zigorra arintze asmotan proposatua, zein lehen pausutzat zeukan horrelako zigorrak kentzeko bidean, heriotzaren zigorraren kontra baitzegoen.

Hilketak eta honen inguruko heiagora eta marraskak maiz ageri dira errepikaturik bertsoetan (I, 7), (II, 1), (III, 9), (V, 7), (XI, 10)...

Eta beste.

Hona irakurleari bere egitekoa laguntzearren transkripzioan egin ditugun moldaketak egungo grafien moldeei jarraiki: aï > ai (aïtac > aitak; ...); aü $>$ au (haü > hau; ...); -ou- > -u- (goure > gure...); y- > j (yuyatu > jujatu; yin > jin...); -y > -i (hogoy > hogoi...); ç-, ce-, ci- > z- (çaharrec > zaharrek; duçu > duzu; cerua > zerua; bici > bizi...); ca-, co-, cu-, -c, cr- > ka-, ko-, ku-, -k, kr- (cantu > kantu; bezarcatu > besarkatu; aïzcora > aizkora; crimac $>$ krimak, cristau $>$ kristau...); ch- > x (cherkha > xerkha; trichtiac > trixtiak; etche > etxe......); gue-, gui- > ge-gi- (gueroztic > geroztik; eguin > egin; yalgui $>$ jalgi; ...); $11>$ il (Guillotin > gilotina...); $\tilde{\mathrm{n}}>$ in (eguin $>$ egin...); - -mb- > -nb- (nombait > nonbait...); -mp- > -np- (exemplu > exenplu...); -s- > -z- (zenbait kasutan, hala nola: gustis > guztiz, isan > izan, san > zan, sembat > zenbat, suen > zuen...)...

Izen propioei dagokienez berean mantendu ditugu, jakin arren orijinala besterik zela zenbaitetan, adibidez, Alsasi (Alsace), Orillac (< Aurillac), Doga ( $<$ Dauga), Paube, ...

Beraz mantendu ditugu euskalkiaren eta egilearen berezitasun guztiak, eta grafien aldaketa soilik egungo irakurketa ohituren eta Euskaltzaindiaren arauen jarraipena kontutan edukita burutu da.

Literatur balioei dagokienez esan behar da gutti estimatu izan ohi dutela kritiko zenbaitek poema eta kanta mota hauek, nabarmenki mespretxatuz. Hala, jada Santillanako markesak, Iñigo Lopez de Mendozak, XV. mendearen erditsutan Proemio e carta al condestable don Pedro de Portugal, deritzan gutunean poesia hiru gradotan banatzen zuen: sublime, mediocre e infimo $^{72}$. Lehenean sartzen dituelarik egile greko-latinoak, bigarrenean probentzalak eta hirugarrenean jende xeheak oso gogoko zituen erromantzeak.

Jadanik hamaseigarren mendean Esteban de Garibayk bere umore beltza, ohiko ziren ixtorioetan agertu zuen, sales gruesas, deitu zituenak, Juan de Timoneda, Luis Zapata de Chaves, Melchor de Santa Cruz eta bestei jarraiki, zei-

${ }^{72}$ Maxim P.A.M. Kerkhof \& Angel Gómez Moreno, 2003, Marqués de Santillana, poesías completas. Madrid, Ed. Castalia, 648. 
nen artean lehena honela hasten zen, Behin errementari batek gizon bat hil zuen eta urkabera kondenatu zuten... ${ }^{73}$

Caro Barojak Romances de Ciego liburuaren ${ }^{74}$ aitzin-solas laburrean kontatzen digunez XIX. mendean Agustin Durán izan zen bere Colección de romances deitu antologian eman ziona romances vulgares delakoei leku eta sailkatze saio bat proposatu zuena, aski zehatza. Baina hain epai ezkorra eman zuen, hainbeste gutxietsi zituen ezen pentsa daitekeen ondorengo ikerlari anitzetan eraginik ukan zuela. Hots, horrelako jeneroa ez zezaketela arima eta esku garbiek uki, ikuspegi estetikotik eta moraletik areago txar eta gaizto zirelako. Iritzi honen kontra idatzi zuen Caro Barojak, herriak hain gogoko zituen erromantzeetan ez baitziren falta balio dramatiko eta gizatiarrak orokorrean, eta hauen pentsamoldeak ezagutzeko apartak zirenez.

Hona zein iritzi ezkorra ematen duen Henri Davensonek ${ }^{75}$ ere:

Dans les années 1880, on rencontrait encore des gens de goût pour s'intéresser aux monstrueuses platitudes des «complaintes» du type Geneviève de Brabant ou Fualdès.

Kantu hauek antzerki ohikoen arabera, hitzaurre moduko bertso formulario batzuekin hasten dira (Pastoraletan Lehen Pheredikiek bete ohi duten funtzio berdinaz), gero kontakizuna edo ixtorioa dator, krimena edo hilketak, -maiz gertatzen zen bezala bat baino gehiago gertatzen zirenean - , alegia, ekintza, eta azken hitzarekin (edo Azken Pheredikia), bukatzen dira, non ekintza odoltsuari darraion zigor exenplu emailea ageriko den, azpimarratuz ixtorioari darion ikaskizuna.

Michel Leclerc, Pont-Neuf-eko kantaria izan zen Parisen XVIII. mendean konplaintegileen artean ospetsuenetarikoa.Honen kanta zenbait aipatzearren hor daude, 1757ko Damiens-en kondemnazionea,Louis XV.ari aizto kolpe batez hil nahi izateagatik, eta 1777ko Desrues-en etsekuzionea Grève-ko Plazan.Egun honetan prezizki, hiru kanta berri agertu ziren Lenoir polizia buruaren baimenarekin Valleyre moldiztegian inprimaturik.

Kanta hauek topikoz eta formulez josiak zeuden, eta Frédéric Chauvaud-ek ${ }^{76}$ azpimarratzen digunez, botereak bere ideologia propioa hedatzeko eta zabaltzeko erabiltzen zituen. Gizartearen natura orokorra baieztatzeko, moralaren garrantzia indartzeko eta betidaniko Ongiaren eta Gaizkiaren arteko borrokaz aritzeko. Noski, Boterearen eta Justiziaren ekintza eredugarriak argi eta garbi uzteko, eta honetarako heriotza zigorra, gilotina ohi zen erabiliko Frantzian XVIII. mende bukaeraz geroztik - heriotze zigorra goxatzearren, antza - eta Espainian urkamendia.

\footnotetext{
${ }^{73}$ Patri Urkizu (itz.), 1987, Behin errementari batek... Garibairen istoriotxoak. Donostia, Txertoa.

${ }^{74}$ Julio Caro Baroja (ed.) 1996, Romances de ciego. Madrid, Taurus, 14.

${ }^{75}$ Henri Davenson, 1982, Le livre des chansons ou Introduction à la chanson populaire française. Neuchâtel, Ed. De la Baconnière, 15.

${ }_{76}$ Joseph, Le Floc'h, aip. art., 101.
} 
Jean Michel Moreau eta Ernest Schnaiter-ek honela pintatzen digute XIX. mendeko konplainten kantaria. Ohol batera igoa, drama odoltsuaren ixtorioa kontatzen diolarik jendetzari.Oihal handi bat dauka aurrez-aurre lau edo sei karratutan banatua, non hilketaren une ezberdinak ageri diren. Bertan hiltzaileak bere aizto izugarriekin zoro moduan dihardu eta biktimek begitarte izutua darakusate.

François du Sorbier ${ }^{77}$ irakasleak Ingalaterrako biografia kriminala aurkezterakoan, beraien zabalkundea, bilakaera eta irakurlegoa ikertzen digu literatura ondorio hauetara iritsiz, alegia, kritikagintzan literatura klasikoa eta herrikoiaren artean ezarri ohi diren mugak faltsuak direla eta hautsi behar direla, bereizketa hau azterketa sakon batek ezabatu egiten baititu. Gaizkileak produkzio idatzian XVIII. mendean, eta geroago ere bai, leku garrantzitsu eta nabarmena hartzen duela egunkarietako ixtorioetan, aitorpenetan, Justiziaren epai-erabakietan, hiltzaileen ixtorio- bildumetan, eta bestetan. Nork ez du ezagutzen, adibidez, Defoeren eleberrietariko baten heroina den Moll Flanders anderea?

Jean-Pierre Seguin-ek ${ }^{78}$ bere aldetik dioskunez, kanta hauetan hainbeste aipatzen da Antzinatea eta erlijioa eta hain da handia exenplu ematearen gogoa koplariaren baitan hilketaren ixtorioa kontatzeari aski leku gutxi uzten diola, eta halaber honelako kantak lekuko aparta direla herri mentalitateak aztertzeko.

Eta Daniel Giraudon-ek ${ }^{79}$ Bretañan hiltzaileen inguruan sorturiko baladak,berrogeita hamarren bat-, arakatzerakoan honako ondorioetara iristen da. Alegia, ikus dezakegula nola bertso-paper horiek erantzun ahal izan dioten frantsesez gutxi alfabetizatua den entzule eta hartzaileari, baina bere txokotik eta bakardadetik atera eta kanpoan zer gertatzen den ere jakin nahi duenari.

XIX. mendean erruz eta modo nabarmenez zabaltzen ari den prentsa, egunkari eta astekarietan elikatzen dela koplakaria. Egunerokotasunean aurkitzen dituela albisteak, batez ere krimenen ingurukoak, bai baitaki oso gogoko dituela gai tragikoak bere entzuleak. Eta azkenik mezuak ez direla batere iraultzaileak, kontserbadoreak baizik, aginte zibil eta erlijiosoak inposatuak noski. Areago oraindik, gertaera tragikoak tratatzeko modu berezi horren bitartez bi sosetan saldu bere bertso-paperekin saiatu izan dela eta ahalegindu bere neurri apalean garaiko bortizkeria eta hilketen kontrako borrokan.

Esamolde patetikoak eta esklamazioak maiz ageri dira ixtorian zehar, aski indar dutenak, hala nola,

Hirur Xefen orena izan dute gilotina! $(I, 12)$

Jujatu izan duzte gilotinatzera! $(I V, 5)$

77 Françoise du Sorbier, 1986, «La biographie criminelle anglaise», Dix-huitième siècle. Littératures populaires. Paris: PU, 167.

78 Jean-Pierre Seguin, 2000, «.Canards»: une succession ouverte», La Bibliothèque bleue \& les littératures de colportage. Ed. Thierry Delcourt \& Elisabeth Parinet, Paris: École de chartes, 185193.

${ }^{79}$ Daniel Giraudon, 2000, «Complaintes criminelles sur feuilles volantes au XIXe siècle en Basse-Bretagne», Violence et société en Bretagne et dans les pays celtiques. Ed. Jean-Yves Carluer, Brest: Centre de Recherche Bretonne et Celtique, 169-198. 
Beraz, ixtoriaren moldatzeko formulak ugari ageri dira eta amaitzeko kantak, maiz moraleja daraman ohiko formulaz bukatzen dira:

Kantu hok eman ditut guziek kantatzeko,

Eta partikulazki neska gaztendako,

Sujeta baita ongi exenplu hartzeko,

Aita-Amak ohora luzaz bizitzeko. (VI, 15)

Balio guzti hauek eta beste asko kontuan hartuta Orixek 1927an Euzkadi aldizkarian plazaratu «Los reos poetas» artikuluan $^{80}$ proposatzen zuen, beti gutxietsi eta ongi ezagutu ez den tradizioa berrirakurtzea eta haien bideari jarraikitzea, beraxek Imozko apezgaiaren kasuarekin egin zuen bezala, ez baitziren ospatzen krimen famatuak, damu handiak baizik:

Invitamos a nuestros poetas que con más éxito pulsan la lira a que fijen su atención en esta fuente, que así se ha enturbiado y aun cegado: a que ensayen la reconstrucción de este género lírico-trágico en historias antiguas o actuales, que no han de faltar; a que no se divorcien del pensamiento y sentimiento de un pueblo, que con tan buen instinto cantó lo que le inspiraba su fe cristiana, formando pie de los grandes extravíos de la humanidad.

Neotradizionalismoaren garaiak ziren.

\section{Kantak eta doinuak}

Iritsi zaizkigun hamahiru kantetarik gehienak, hots, hamaika egitura honetakoak dira: 13 AAAA. Hots, lauko hamahirusilabadunak dira bertsoak. Lehena (18 AAAA), eta laugarrena ezik (13AAA 6 A 13 A 6 A), beraz ez dezakegu esan arlo honetan aldaketa anitz eta ugaritasunik dagoenik, baizik eta tradizio ohikoari (Bordaxuri...) jarraikitzen diola.

Kanten doinuek zabalkundean garrantzi handia zuten, noski. Eta gehientsuenek zerabilzkiten aireak lehendik jada oso erabiliak, usatuak ziren, orok ezagutzen zutena eta kantatzen zekitena. Hala, Histoire tragique et morale d'un ci-devant épicier-droguiste faussaire et empoisonneur titulua daraman bertso paperak, hots, botikari faltsu eta pozointzalearen kontrakoak 1676an, beraz mende bat lehenago, ezaguna zen Lully-ren Atys tragedia lirikoaren koru baten doinua zeukan, eta 1723az geroztik Brabanteko Genobebaren baladaren doinua bilakatu bide zen.

Jean Baptiste Orpustan ${ }^{81}$ ikerlearen arabera, Borthegaray urkamendira doaneko kanta, Lambert apaiza, vulgo Belça, hiltzeagatik 1723. urte ingurukoa litzateke, eta beraz, tradizio honen lehenetarikotzat jo dezakegu.

${ }^{80}$ Euzkadi, 1927-V-27.

81 Jean Baptiste Orpustan, 2002, «La chanson de Borthagaray » «Urzaiz», La vallée d'Ossés en Basse-Navarre. Orzaizeko Ibarra. Bidarray, Ossés,Saint-Martin-d'Arrossa. Baigorri: Ed. Izpegi, 265-273. 
Iraultza garaian zertxobait gutxiagotzen diren arren krimen eta zorigaitzen gainean moldatu kantak, XIX. mendean berriro ugariak izan dira. Pariseko Liburutegi Nazionalean milaka complainte aurki daitezke frantsesez. Hauen artean, gutxi batzuk euskaraz, oso gutxi gure gogorako, baina ez horregatik zokoratu edo baztertu beharrak, esan nahi digunak oroitzen baditugu Michelen hitzak anitz galdu bide direla.

XIX. mende hasieran, 1817an justoki, Rodez-en hil zuten Fualdès magistratua, eta honen hiltzailearen epaiketa oso kasu famatua bilakatu zen. Eta gutxienez bi konplainta moldatu ziren okasio askotan kantatu zirenak, zeren geroago moldatuko diren hainbat eta hainbat kantu berrik honako oharrak dakartzate: Sur l'Air de Fualdès, eta Sur l'air de toutes les complaintes. Alegia, Fualdèsen doinuaren arabera.

Halaber Gure Herrian ${ }^{82}$ ematen dutenean 1815eko Bordaxuriren edo Galerianoaren kantuak Nehor eta C. Dufau-k azpititulu hau ezartzen diote: Krima itsusi guzien airean.

Hona Etcheparek erabili zituen doinuak bere euskal kanta berrietan:

1. Kriminelak bethi hatzemanak dira orotan (I)

2. Aita saldu nuzu idi bat bezala (III, XI)

3. Ura eta arnua (IV)

4. Kantatzera niazu alegera gabe (VI)

5. Nahi gabe ainhitz da mundian gerthatzen (V, VII, X)

6. Pena dut eta dolore (VIII, XII)

7. Lau punduko airea (II, IX, XIII)

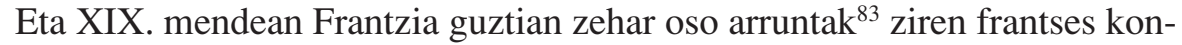
plaintetan bezala Etcheparek besteok ematen dizkigu:

1. Air de Fualdès

2. Maudite neige, tomberas-tu toujours?

3. Beranger à l'Academie ou

4. T' en souviens-tu?

5. Laissez les roses aux rosiers

6. Le vin et l'eau.

7. Mon gaillarde Eugène.

${ }^{82}$ GURE HERRIA, Baiona, 1922, 20.

${ }^{83}$ Hona adibide bat: «Chant funèbre sur la mort du Duc D’Orléans, prince royal», Air: Maudite neige, tomberas-tu toujours?, Ach Eyraud, Histoire de Son Altesse Royal e Monseigneur le Duc D'Orléans racontées aux enfants. Dupin, Paris, 1850, 11. 
Bitxia da ere nola azken aire hau, Madragueko krimenaz ari delarik, dioen zehazki: Chantée et vendue par les époux ETCHEPARE. Eta konplaintaren egilea bezala Maurin delako bat ageri da. Ez da, egia esan, oso ohikoa bertso-paperetan agertzea zein den kantaria.

Labur biltzeko azpimarra dezagun Kantu Berri hauen bitartez, Jean Etchepare, koplari bretoiak bezala ahozko tradiziotik zenbait elementu gordez (airea, hasiera eta bukaerak), aldendu egiten dela beraietatik, eta modan zeuden gazeta idatzizko ixtorioetara hurbiltzen, hauetan bezala kasu zenbaitetan irudiez baliatuz testuaren garrantzia, trajikotasuna indartzeko.

Justo irundarrak Troppmann hiltzaileari buruzko bertsoak idazterakoan ere berdintsu bere lan modua argitzen digu 26. bertsoan: Orra verso berriyac / Justoc jarriyac / cergatic letu duen / Parisco historiyac.

Halaber Etcheparek hitz lauz eta modu xume batez ematen dizkigun asasinamenduen explikazioniak direlarik eramaten gaituzte esatera, frantsesez deitu canard ixtorio beltzen kontakizunetarako bidean saiotxo bat baitira, aitzindari dugula euskal literaturaren esparruan.

Urkamendiko baladen tradizioari jarraiki (Aphez Beltxa, Larralde Bordaxuri, Pierre Topet Etxahunen Luistto Irixibauren hil-eresia,...) Manex Etchepareren kantuak aitzina urrats bat direla ezin uka. Eta kontuan hartzen baditugu bertso-paperen inprimalekuak (Baiona, Miarritze, Orthez, Akize, Pau, Foix...) eta euskaraz ez ezik frantsesez ere idazten zituela konplaintak gaiztaginen kontrako bere mezua ez zen mugatu Ipar Euskal Herrira soilik, Pirineoko beste herrialdeetan ere barreiatu bide zen.

Donostian, 2010eko otsailaren 11an 


\section{KANTU BILDUMA}

I

\section{KONPLAINTA DOLOROSAK ${ }^{84}$}

Marseillako Probentzian, hamalau Brigant Italianuek egin duzten hamar Asasinamendu Krudelen gainian 1873an emanak

Airia: Kriminelak bethi, hatzemanak dira orotan

1. Kantu berriak agertzen dira argi diten ignorantak,

Zeru-Lurrak harritzen ditu orai izan den sujetak,

Horietaz mintzatu dira gaztiak eta zaharrak,

Zer kriminelak izan diren, nazione liferentak! (bis)

2. Brigant banda handi bat agertu zauku Frantzian,

Obra lazgarrienak egin Marseillako probentzian,

Mundu guzia harritu da sujet horien gainian

Holako gaixtakinak badirenez Italian?

3. Hamar etxe asasinatu Frantziako lurrian!

Bertze zazpi erre dituzte familiak aintzinian!

Haur aingeru gaixo batzu Jainkoari gomendian,

Lurrerat othoi beha dezan heien oren tristian!

4. Oren gaixtuan sorthu denak hedatzen ditu banderak,

Haren gorphutzaren saria sekulako galerak!

Exenplu har dezagun orok zer diren jende krudelak,

Hirur xefa aintzindariek ixuri duzte odolak.

5. Jende guziak harriturik, bortha leihuak serraturik,

Gau eta egun egon dira barnian beldurturik.

${ }^{84}$ Orthez, J. Goude-Dumesnil, 1873. 
Ohoin, Brigant banda hori elkarrenganat bildurik,

Present huna arribatu da Italiaren aldetik.

6. Zer nahi egin dute Marseillako probentziari,

Asasinatu onduan su emanez etxiari,

Familiak oihuka zauden Zeruko Jainko jaunari,

Othoi, arresta dezan masakre krudel hori!

7. Marseillako probentzian da sujet hori arribatu,

Heiagora eta marraska ${ }^{85}$ ez dute kontsideratu,

Beren etxiaren barnian dituzte asasinatu.

Zer nahi eginen zuten ez baliuzte arrestatu.

8. Brigant horiek izan dira arrestaturik Armadaz,

Eta gero mainotatiak bi jandarma brigadaz.

Zer nahi sofritu izan du hango jendiak denboraz!

Sekulan orhoituko dira Italiako banderaz.

9. Zaldiz juan zen armada Briganten arrestatzera,

Jandarmak heiekilan lurpeko leize batera,

Obligatiak izan dira ordian errendatzera,

Justiziaz gastigatzeko gobernamendu justora.

10. Hamalau Brigant izan dira arrestaturik ordian,

Lau emazte konpainiako heiekilan batian,

Merkhatu bat bildu izan da horien jujamendian,

Bi ehun destamonio ${ }^{86}$ bazen kondenamendian.

12. Galetto eta Gabarino, Xef-Nausia Fontana,

Justiziak ez dezake beste gavizetan ${ }^{87}$ kondena.

${ }^{85}$ Heiagora eta marraska, maiz ageriko dira bi izenok loturik.

${ }^{86}$ Destamonio (sic), lekuko, testimonio.

${ }^{87}$ Gavizetan (sic), gauzetan. 
Exeko Asisetan ${ }^{88}$ punitu dute obena,

Hirur Xefen azken orena izan dute gilotina!

14. Bertze hamekak aldiz sekulako galeretan!

Lau egun pasatu dute jujamendu horietan.

Bazen han jende frango horien azken hitzetan,

Urrikalmendu guti holako krimineletan.

14. Martxuaren hamabian altxatu zen gilotina,

Hirur xefa horiendako justiziaren ordena!

Huna nolakoa izan den Briganten azken orena,

Galetto eta Gabarino, Fontanaren zori huna!

15. Jujamendu hori izan da Exeko Asisetan ${ }^{89}$,

Mila zortzi ehun hirur hogei hamahiruan,

Eskerrak errenda ditela hango juje nausietan,

Arte hartan bizi baiginen etsaien aztaparretan.

$* * * * * * * * * * * * * * * * * *$

Reproduction interdite.

Propriété de l'auteur. Jean ETCHEPARE de Saint-Palais.

Briganten izenak eta adinak:

Fontana, 20 ans; Galetto, 25 ans, Gabarino, 33ans; Joseph Trinchieri, 31 ans; Jacques Ribetto, 46 ans; Joseph-Pascal Montegazzo, 38 ans; Baptiste Bellora, 27 ans; Joseph-Mari Montegazzo, 37ans; François Reynaud, 23 ans; Jean Vercellone, 46 ans; Angèle-Marie, femme Arezzo, 38 ans; Marie Siméon, veuve Pourianne, 35 ans; Françoise-Madeleine, 33 ans; Marie Galigalis, 17 ans.

Orthez Typ. J. Gaude-Dumesnil.

${ }^{88}$ Exeko Asisetan, Aix-en-Provence-ko Justizia Jauregian.

${ }^{89}$ Grand Drame judiciaire. Cour d'Assises d'Aix (Bouches-du-Rhône). Quatorze accussés. Deux condamnés à mort. BNF FM-8815. Agiri honetan piemontetarren izenaketa adinak zerbait ezberdinak dira, baina orotara aipatu hiltzaileen kopurua berdina: hamalau. Hala, Joseph Fontana-k, alias Cachim eta Romagnol deituak 36 urte ditu; Louis Garbarino, Le Bachin deituak, 33 urte; eta Antoine Galetto, Bochon deituak 20 urte.. 
II

VILLE DU HAVRE-REN HONDORATZEA ${ }^{90}$

Lau ponduko airia

1. Untzi bat galdu zauku itsaso handian,

Berrehun bat pasajers juan da barnian,

Heiagora, marraska bazen han ordian,

Jaunari gomendatuz azken orenian.

2. Frantzesa zen untzia Montobidoetan ${ }^{91}$,

Komersan zabilana zonbeit urthe huntan,

Errekontru gaiztua izan da heietan,

Erremarka bazuten hirur egun hartan.

3. Montobidoetarik lau egun orduko,

Abisa ukhan faltaz etziren galtzeko,

Odei bat jelgi zaie bistaren galtzeko,

Urak iretsi ditu argitu deneko.

4. Gerlako untzi handi angles batendako ${ }^{92}$,

Malurra ukhan dute elgarren joiteko,

Azken oren tristia harek eman dako,

Othoitz egin dezagun gure arimendako.

5. Hirurehun pasajers, gehienak galdu,

Lauetan hogoieta bederatzi salbu,

Noiz eta direnian leihorrerat heldu,

Ama birjinak ditu bere haurrak bildu.

90 1876. M Fiche BNF, YO-2. COMPLAINTE sur l'épouvantable naufrage de la «Ville du Havre», Le navire français percé par le navire anglais... 226 passayers ithoric... Bada lehenago ere moldaturiko kanta bat F. Michelek bildua (Le Pays Basque, pp. 348-352), basa nafartarra, PULUNPA deituraz.

${ }^{91}$ Montobioetan (sic), Montevideotan.

92 LOCH EARN izenekoa. 
6. Untziko kapitaina oihuka hasi zen,

Jenden kontserbatzeko baxetak non ziren?

Hiruretarik biga hautsiak baitziren,

Ororen salbatzeko bat baizikan etzen.

7. Nigarrez juan dira othoitz egitera,

Ama zu heldu zira arimen bidera,

Harriturik jarri da itsasoa bera

Nolakoa izanen den jainkuaren kolera.

8. Ameriketan zer da? Urhia metaka,

Irabaziak altxa khondiak egin eta,

Beren ustez juanak fortunaren xerkha,

Anhitzak han dabiltza eske borthaz bortha!

9. Sorthu orduko haurrak, oro Amerika,

Fin hunaren egiteko xedia gal eta

Aberasten balira zuzenaren kontra,

Anhitzak heldu dira bertzenaz har eta.

10. Frantziako haurretan badut konfidantza,

Ameriketara alde ez gitela mintza.

Hemen trabaila giten manera hon gisa,

Zuzenian behar da gozatu intresa.

11. Bakotxak bere lurra ez du behar utzi,

Bertzela izanen da etsaia nagusi,

Diela zenbeit urte baitugu ikhusi,

Gu Ameriketan, soldado ihesi !!!

12. Hementik juaiten dira ontsa direlarik,

Aita-ama maitiak etxian utzirik,

Menturaz gehiago hetaz ez khasurik,

Zahartzen direnian ez dute jaberik. 
III

\section{INONDAZIONE BERRIEN GAINIAN ${ }^{93}$}

Airia: Aita saldu nuzu idi bat bezala ${ }^{94}$

1. Mila zortzi ehun eta gehiago dena,

Hiruetan hogoi eta hamabortz garrena ${ }^{95}$,

Hau da mirakulia agertu zaukuna!

Jaun handiak itsasoz igorri daukuna. (Bis)

2. Holakorik ez da izan gure probentzian,

Ehun eta bortz urthe juan den maiatzian,

Exenplu hori altxa gure bihotzian,

Zonbat mirakulu den jadanik Frantzian.

3. Destruitu izan da horren bertze jende,

Alde guzietarik heiagora zaude,

Galdu diren gaixuak aingeruak daude,

Eta bizi dirinek egizie inbide! ${ }^{96}$

4. Zertako eman dira kantore berriak?

Erresuma orotan daude harritiak!

Karitate egin du Uropa ${ }^{97}$ guziak,

Anhitz gisetan badu gaztigu Frantziak.

5. Tolosan galdu dira zazpi ehun etxe

Eta bi mila jende itho dira hantxe,

93 Titulu osoa: INONDAZIONE BERRIEN GAINIAN ZONBEIT BERTSU BERRI GUZIEK KANTATZEKO EMANAK Bayonne: imp. de C. Lousteau, 1876. BNF. YO-1.

${ }_{94}$ Doinua jada ageri da 1857an, F. Michel, aip. lib., 265.

95 Uholde eta inondazio ikaragarriak izan ziren 1875eko ekainaren 23an Aturri ibaian eta Frantziako Tolosako inguruetan.

${ }_{96}$ Dirinek (sic) egizie inbide !, bizi direnak egizue eginbide !.

97 Uropa (sic), Europa. 
Oihu egiten zuten, ah! bainan berantxe !

Fagore egiliak sobera urhuntxe !

6. Exenplu hori ez da Tolosan bakharrik,

Anhitz Departamendu bada funditurik,

Jaunaren goberniaz larderiaturik,

Ez daiteke desira nehork kalterik !

7. Anhitz jende badira esklabo jarriak,

Lehen aberats eta orai aldiz probiak,

Urak eremanikan huntarzun guziak,

Eskapatu dituzte bakharrik biziak.

8. Presidenta jin zauku jaunak Parisetik,

Malurren ikhustera handizki gogotik.

Orok aithor dezagun gure bihotzetik,

Horrek salbatu gaitu ororen gainetik.

9. Aita amak nigarrez haur gaixuen ondotik,

Heiagora, marraskaz, teilatu gainetik,

Abertimendu hori jautsi da zerutik,

Nigar egin dezagun holakoen gatik.

10. Gauza lazgarrienak izan dira aurthen,

Oro harritu dira ustez hil behar zen !

Zer phenak izan diren hasi niz erraiten,

Ez dakiten guziek konpreni dezaten.

11. Zazpi ehun etxe eta bi mila presuna,

Hona nonbria non den galduen izena,

Erauntsi handi horrek Tolosan egina,

Buluzgorri dabila eskapatu dena. 
12. Anhitzak bildu dira arbola gainetan,

Khausitzen ahal zuten lekhu guzietan,

Anhitz entsegu bazen oro alferretan!

Itsasorikan baizik etzen bazterretan !

13. Beldur izan behar da tenpesta handier,

Tolosan eman daukun exenplu guzier,

Oro oihuka zauden bere adikidier,

Bazterretik zaudenak ez baitziren fier !

14. Familia osuak badira galdurik,

Urak altxatu ditu phentsatu gaberik,

Etxiak zimendutik, arbolak errotik,

Aita amak nigarrez, haur maitiak ondotik.

15. Karitatez heldu da anhitz nazione,

Fagore egiterat jinak dira erne,

Gu ere altxa giten haur hilentzat berme,

Mac Mahon ${ }^{98}$, egizu zuk atenzione ${ }^{99}$.

98 Marie Edmé Patrice Maurice Mac-Mahon, Mac Mahon-go kondea, Magentako dukea eta Frantziako mariskala,1808ko uztailaren 13an jaio (Sully, Saône-et-Loire) eta 1893ko urriaren 8an hil zen (Montcresson, Loiret). Militarra eta politikoa, Frantziako Presidente izatera iritsi zen. Hirugarren Frantses Errepublikako bigarrena, 1873ko maiatzaren 23tik 1879ko urtarrilaren 30era. Etorki irlandesekoa zen, XVII. mende bukaeran Frantziara emigratu zuen familia batengandik baitzetorren. Oso kontserbazale izan zen.

${ }_{99}$ Ondoren honako dator frantsesez: Jean Etchepare. Propriété réservée de Jean Etchepare. Tout contrefacteur sera poursuivi selon la rigueur des lois. Bayonne, Im. Ch. Lousteau, rue Boufflers. 


\section{IV}

\section{LA TOMBELLE BAROINAREN ASASINAMENDUA ${ }^{100}$}

Airia: Ura eta arnua

1. Deklaratzen hasten niz berri triste baten,

Orok entzunen dute sujeta nola zen,

Tolosako onduan jauregi eder bat zen,

Jauna ganberan zen,

Aizkora handi batez bi kriminelek hiltzen:

Bata muthila zen. (bis)

2. Baroina bere ganberan martir hil hotza!

Kriminel malerusek hun zuten bihotza,

Kabala baten gisa buria zuen arraildia,

Jaiki da gorphutza,

Bigarren ukhaldian khendu dakotxatza,

Ukhaiteko moltza.

3. Holakorik ez da izan Frantziako lurrian,

Jainkuaren botheria han zen agerian,

Buria oso gelditu da gorphutza erre denian,

Aingeruak guardian,

Hola nola agertzen den sujet gaizto denian,

Galdu behar denian.

4. Haren gorputz martira memento berian

Lehenikan hil dute, gero erre jauregian,

100 Titulu osoa honakoa da: Arrêt rendu pour la Cour d'Assises de la Haute-Garonne. Le crime d'Empouillac, assassinat de M. le baron de la Tombelle. Audiences des 2, 3 et 4 mars dernier. Affaire Mitron \& Lasserre, leur condamnation à mort et leur exécution. Pau, Imprimerie Veronese. Impasse le Fol. Complainte sur l'assassinat de M. le baron de la Tombelle. Éxécution de Mitron, âge de 28 ans et de Lasserre, âgé de 42 ans. BNF, Microfiche YO-2.

Bada complainte bat ere frantsesez Augustin Sarrieu-k idatzia hamaika bertsotan, lehenik ixtorioa hitz lauz eman ondoren (1874); eta eleberritxo bat Armand Praviel-ek idatzia: «La mort mistérieuse du baron de La Tombelle» (La Revue Belge, Bruxelles, 1936, 289-323.) 
Oihuka hasi dira su dutela etxian,

Eta jaunaren ohian.

Hiriko populia han bildu denian kolpia ordian

Agertu burian.

5. Mirakulu handia zen bien akordatzia,

Fite konposatzen da gaiztoaren tratia,

Ebatsirikan ere haren diru guzia,

Utzi bere bizia!

Jujatu izan duzte gilotinatzera!!!

Horra heien grazia.

6. Jauna bere etxian erre izan dute,

Holako kriminel arima nun dute?

Tolosako hirian jujatu izan duzte,

Gilotina bite,

Gero goza dezaten ontsa egin badute,

Hementik juan bite.

7. Berak lurrian galdu dira, zeria menturan,

Egin duten krima handiaz bethikotz arranguran,

Gero zer izanen den nehok ez diro erran,

Hementik landa han;

Arima juan da koleran, gorphutzak ez diro jasan

Karga handia han.

8. Krima handi hori gerthatu da Tolosan,

Holako akzioniak ez dira ardura izan,

Zerua bere argian lurra bere justizian,

Hori ez diro jasan!

Hemen hiltzera kondena, ifernia balantzan

Erraiten duten gisan. 
9. Bigarren justizia Zeru-Gorenian

Arimak hartuko da azken orenian,

Besuak zabaldurik oihuka zaudenian

Hiltzerat abian

Miserikordiarik ez duten tenorian

Nigarrez ordian.

10. Izpiritu gaiztuak gizonen barnetik

Penak emaiten ditu plazerren ondotik,

Mundu huntako bizia bertzia ahatzirik,

Diru tzar baten gatik!

Alferren eta gormanten jokolariengatik

Satan heldu da Ifernutik.

11. Kantu hok eman ditut ez libertitzeko ${ }^{101}$,

Inbide gaizto duten jenden abertitzeko,

Mundurat jiten gira denbora gutindako,

Ez jakin zenbatendako,

Ontsa goberna gaiten mundutik juaiteko

Gero khondu emaiteko.

\section{V}

AKZIONE KRUDELEN GAINEKO KONPLAINTA DOLOROSAK

1876an emanak ${ }^{102}$

Airia: Nahi gabe anhitz da mundian gerthatzen ${ }^{103}$.

1. Orai huna non diren kantore berriak,

Estranjerrak baitira sujeten jabiak.

\footnotetext{
101 Orijinalean libertcico (sic).

102 Bayonne, Impr. C. Lousteau 1876. BNF, YO-1.

${ }^{103}$ Honela hasten da Arnegiko heriotzaren gainean deitu kanta (1864).
} 
Akzioniak dira dolorosgarriak, (Bis)

Egin izan dituzte gauza lazgarriak. (Bis)

2. Zerua eta lurra dituzte harritu,

Desordre itsusiak ditugu aditu,

Oihan beltzian dira brigantak agertu,

Berrogoi eta biga dituzte khondatu.

3. Badira Prusiano, bai Italiano,

Batziak hilak eta bertziak galerano;

Zer nahi egin dute hatzeman artino,

Oihan beltzeko leize barnian zaudeno.

4. Huna lehenbiziko krima itsusia,

Hogoi eta hamazazpi asasinatzia,

Ehun bat ohointza da, biez phasatia,

Eta bortz Elizetan ezpaita hobia.

5. Lorrenako fronteran, Alsazeko juntan,

Oro harritu dira juan den denboretan,

Zer nahi frauda bazen bide bazterretan,

Eta asasinatzen dilijentzietan.

6. Bi nazionetarik juntatu brigantak

Oihan beltzian zauden, jente elegantak!

Harrigarri baitziren hetan ziren plantak

Sahetsak oro harma, eskuetan lantzak.

7. Andere gazte bat zen jauregi batian,

Tronpatu izan dute phentsatu gabian,

Bai eta lau phusketan ezarri leizian,

Heiagora marraskaz hek irri ordian. 
8. Neskatoren aita oihuka ari zen,

Oraino ez zakien haurra non othe zen;

Kabala baten gisa lau phusketan baitzen

Brigant horien xefak guziak harritzen.

9. Heien arrestatzia, han da harrigarri,

Aita hura lothu da brigant nausiari,

Orai aski egin duk, erretira hadi!

Ordian aithortzen du krima handi hori.

10. Prusiako soldado eta paisantak,

Harenbertze jandarma, hek ziren frantzesak,

Hala ere azkar ziren brigant horien xefak,

Ezin errendaraziz, hil dute hamar bat.

11. Hamar hirur dituzte hiltzerat ekharri !!!

Bertziak galerano bethikoz igorri,

Huna nola jarri den brigant banda hori,

Kriminelak zer diren exenplu har bedi.

12. Beldur izan behar da gizagaistoari,

Hura konparitzen dut heriotziari,

Phentsamendu gaiztuak orai edo sarri,

Satanen banderetan egiten du irri.

13. Gizona bestitzen da kalitate oroz,

Gorphutza ontsa eta arima maloros,

Bere biziaz hila ez dezake eros,

Ontsa goberna gaiten izaiteko uros.

14. Lorrenako fronteran fama handia zen,

Hango jendiak oro harritiak zauden, 
Nontik nor jalgiko zen begira baitzauden,

Gaiztoaren orenak ziren baliatzen.

15. Hamahirur gilotinatu, bertziak galeretan,

Burdinaz kargaturik presondegietan,

Zer abertimendiak seinale orotan,

Exenplu har dezagun brigant horietan.

VI

MARSEILLAN IZAN DEN ASASINAMENDU BATEN GAINIAN

KANTU BERRIAK ${ }^{104}$

Airia: Kantatzera niazu alegera gabe.

1. Kantatzerat niazu berri triste baten,

Orok entzunen dute sujeta nola zen,

Holako krimarikan ez dugu ikhusten,

Zerua eta lurra batzuek harritzen.

2. Frantzian izan dira laido itsusiak,

Krimaren arabera dira jujatiak,

Berak agertu ditu oh! esperentziak,

Pietate gabeko amaren umiak.

3. Marseilla deitzen duten hiri ederrian,

Andere gazte bat zen ezkontzaz abian,

Amodioa zuen barna bihotzian,

Amak ez ametitzen jaun haren hartzian.

${ }^{104}$ Dax, Impr. Nouvelle, 1882. BNF, RES ATLAS Z 52 (A, 2, 3), f. 2r. 
4. Amari galdein dute ezkontzeko botza,

Maleruski eman du errepostu hotza,

Fite ezarri dute martier hil holtza,

Ganibetian trebe baitzuten bihotza.

5. Ama bere alabaz asasinaturik,

Ez duelakotz eman permisionerik,

Alaba hazi balu larderiaturik,

Ez zaion gerthaturen segur holakorik.

6. Senhar emazte gaiak ziren alegera,

Prestatu zirenian amaren hiltzera,

Libratuko zirela gero ezkontzera.

Ordian zabaldu zen gaixtuen bandera.

7. Heiagora marraskaz ama maite hura,

Othoi, ene alaba, emadan denbora,

Kontrizionia bederen ez dinat sobera,

Ez baitu permetitu haren egitera.

8. Hil eta onduan gero laurdengatu dute, Itsas bazter batian ihortzi baitute,

Guarda gomendant batek hatzeman du fite,

Jandarmeriak laster arrestatu duzte.

9. Ama haren gorphutza lau pharte egina,

Lehen ganit kolpia bihotzian barna,

Zonbat krudela zuen, oh! azken orena!

Jainko jauna har zazu zuk haren arima.

10. Marseillako andere ezkondu nahia,

Horra nun den Vitalis gilotinatia, 
Amari egiteko zer akzionia,

Martier hil onduan zuk laurdengatia!

11. Marseillako hirian gerthatu sujeta,

Krima handiagorik ez daiteke gertha,

Heriotzek lazgarri krudelena baita,

Ezkondu nahi zuten, oh! ama hil eta.

12. Horra bi kriminelak eta heien obrak,

Harritu tu itsas bai eta leihorrak,

Ez zituzten hobiak ondoko denborak

Jauna gilotinatu alabak galerak.

13. Maria Boyer zira segur malorosa,

Galdu duzu arima, zure erresusa,

Zeruko Jainkoari egiozu adresa,

Horra barkamendutan zitzan mortifika.

14. Bi belhaun buluziez herrestan bidian,

Oihan eta desertu guzien artian,

Ibili behar zira tristia mundian,

Nahi baduzu pharterik zeruko lorian.

15. Kantu hok eman ditut guziek kantatzeko,

Eta partikulazki neska gaztendako,

Sujeta baita ongi exenplu hartzeko,

Aita-Amak ohora luzaz bizitzeko. 


\section{VII \\ BRIGANTEN JAUREGIA ${ }^{105}$ \\ Kantu Berriak Hamalau Briganten eta \\ Hamazazpi asasinamenduen gainian emanak}

Airia: Nahi gabe ainhitz da mundian gerthatzen.

1. Huna kantu berriak aire zaharrian,

Deklaratzen hasten niz Heskual Herrian,

San Modina deitzen den hiri ederrian,

Hamalau kriminelen sujeten gainian.

2. Itsasoz bertzaldian San Modin hiria,

Philippineko isla da izendatia,

Brigant banda handi bat han zen agertia,

Oihan baten erdian zuten jauregia.

3. Jaunak orai nahi dut mundia argitu,

Krima nahi duenak ongi konprenitu,

Hamazazpi neskatxa dira destruitu,

Hemezortzigarrena baita kontserbatu.

4. Hirur urthez faltatu andere gaztiak,

Jose Pozzolek ditu hatzeman guziak,

Tratamendu krudelak errezibitiak,

Zer miserikordiak galdurik biziak !

5. Jose Pozzolek zuen kuraie handia,

Oihanaren erdian brigant jauregia,

Hartan hatzeman dute bizi Anderia,

Bertze zonbaitek zuten han galdu bizia.

${ }^{105}$ Dax, Impr. Nouvelle, 1882. BNF, RES ATLAS Z 52 (A, 2, 3) 
6. Jose Pozzol juan zen lasterrez hirira, San Modinako jujer pharte emaitera,

Tropa igor dezaten hen arrestatzera

Horrek gidatu ditu briganten leizera.

7. Pedro Bendarez eta Stephano Diaz,

Xefa nausiak ziren briganten kargiaz,

Bai eta garniturik ziren harmeriaz,

Ez baitzuten beldurrik gilotinatziaz.

8. Hamazazpi neskatxa konsomitu hurran,

Zonbat sofritu duten ez daiteke erran,

Hemezortzi garrena bizirik ganberan,

Kontrizioniaren eiteko maneran.

9. Haur gaixuak oihuka aita eta ama,

Bai eta gomendatzen gure jainko jauna,

Martierren gorputzak uros du arima,

Orai gozatzen dute zerurik Gorena.

10. Pedro Bendarez zuten esposatzalia,

Signifikatzen zuen aphezen ordia,

Krima handia da hori jujatia,

Guziek har dezagun hortan exenplia.

11. Pedro Bendarez eta Stephano Diaz

Hiltzerat kondenatu dira justiziaz,

San Modina hirian gilotinatziaz,

Zortzigarren baitziren beren konpainiaz.

12. Zortzi gilotinatu hamalauetarik,

Sekulako galerak lauek heietarik, 
Nehon ez da agertu holako krimarik,

Ez baitzuten phensatzen bazela lanjerrik.

13. Brigant azkenak biak presundegietan,

Hogoi urtherendako kondenaturikan,

Orai paga ditzazten penitentzietan,

Egin dituzten krimak beren denboretan.

14. Kanta kantu berriak dolorosgarriak,

Hamalau krimenelen miserikordiak,

Ontsa gostarik hazi aitamen umiak,

Briganten eskuetan galdurik biziak.

15. Jainko jauna, jeuts ${ }^{106}$ zaite lurraren gainera,

Akzione krudelen justifikatzera,

Aingeruak ondotik odeier behera,

Andere martierren ${ }^{107}$ arimen bidera ${ }^{108}$.

\section{VIII}

\section{KANTU DOLOROSAK 1888AN EMANAK AINGERUEKIN DAGO ${ }^{109}$}

Airea: Pena dut eta dolore

1. Kantu berriak guziek kantatzeko,

Sujetak trixtiak dira khundatzeko,

106 Jeuts (i), jeitsi, jatsi.

${ }_{107}$ Martier, martiri.

${ }_{108}$ Azpian frantsesez: Jean ETCHEPARE. Complainte sur le rapte de 18 jeunes filles (5 estrofa). [...] Parisen laur urtheco haur bat içan da berrogoi eta hirur pusketan ezarririk. Courrier bat assesinaturik. Eman dugu heyen cantiac, cembeit egunen burian. ASCAINECOAC ERE.

${ }^{109}$ Euskaltzaindiko Liburutegia. Lacomberen artxiboa, bertso paperak, 554. zkia. BNF, Z Basque-29.

Xabier Kaltzakorta, 2002, «Jean Etchepareren cantu dolorosac». KARMEL n. ${ }^{0}$ 230, 35-55. Joanito Dorronsororen arabera (Bertso doinutegia, 1995) 2169, Aitak eta amak herritik (N). Pena dut eta dolore. 
Ama-seme batzu baziren Orillako, ${ }^{110}$

Mundua harritu baitute sekulako.

2. Emaztia alharguna zen munduan

Esposa hila zuela ez goguan,

Semiarekin erori da bekhatuan,

Etsai zaharra etzen naski ifernuan.

3. Haur bat egin eta hil du gordatzeko,

Semiaren ohorea beratzeko.

Matalazen artian eman ithotzeko,

Uste zuten nehor etzela ohartuko.

4. Ama krudelak zer krima egiteko!

Ithotzea etzen aski harendako!!

Marraza $^{111}$ batez xehatu du finitzeko,

Bertz batian gero ekarri egozteko!!

5. Haren gorphutza bertzian urtharazi ,

Satan gaixtuak hola du galarazi,

Aingeru gaixuak etzuen ez merezi,

Sorthuz geroztik behar dira oro hazi

6. Biharamunian jalgi zen kanpora,

Auzoko emazte batek erran gora,

Zer egin zuen bezperako karga hura?

Krimenala bera galtzen da, bai ardura.

7. Komizariua zuten abertitu,

Berheala jandarmekin da partitu,

110 Orillako, Aurillac-eko

111 Marraza, harakinaren matxetea. 
Etxe hura behar zutela bisitatu,

Gaizkiaren marka guziak hatzeman tu.

8. Ilherrietan izan da justizia,

Ama-semiek harturik konpainia,

Erran baitzuten han zutela ihortzia,

Bainan haurrik khausitu gabe jalgi dira.

9. Ama-semiak dituzte arrestatu,

Haurra zer egina zuten atakatu?

Ama krimenelak orduan du aithortu.

Bere krima izigarria deklaratu.

10. Jujatuak izan dira asisetan,

Ama-seme horiek ziren obenetan,

Semia sekulako eman galeretan,

Bizia behar du pasatu burdinetan.

11. Amaren jujamendua gilotina,

Aphez batekin eginik etsamina,

Kurutzefika bat eskuan baitzen jina,

Hola izan da ama haren azken fina.

12. Gaztigatu izan ditu Jinko-jaunak,

Harek egiten baititu lege hunak,

Xuxen gidatu behar dira bethi haurrak,

Etsenplu har zazue huntan, aitamak. 


\section{IX}

\section{KRIMA LAZGARRIA ${ }^{112}$}

Lau punduko airian

1. Nahigabe anhitz da izaten munduan,

Sujet hau gerthatu da Lurdeko onduan,

Guzientzat lekhua delarik zeruan,

Zonbeit behar da naski bethi ifernuan.

2. Senhar-emazte batzu ziren elgarrekin,

Etxian bizi ziren beren lau haurrekin.

Hirur neskatxa eta muthiko batekin,

Maleruski gerthatu dira amarekin.

3. Alabarik etzuen ama harek maite,

Eta semiarentzat dena borondate.

Aitak ezaguturik erran dako fite,

Diferentzia horrek ekharri dio kalte.

4. Egun oroz zabilan aita lur-lanian,

Haur gaixuak utzirik amaren aldian,

Bi alaba gaztenak hil ditu ohian,

Aizkora bat harturik xehatu ordian!

5. Hirurgarrenak sanja baitzuen ganbera,

Memento bat egon da juaiteko hiltzera,

Aita arribatu da artian etxera,

Eskutik khendu dako amari aizkora.

112 Cantu berriac 1888an emanac CRIMA LAZGARRIA Lau punduko airrian. Xabier Kaltzakorta, 2002, «Jean Etchepareren cantu dolorosac». KARMEL n. ${ }^{\circ}$ 230, 35-55-.BNF Z Basque -29.

Ikus: Factum Gertrude Cherroux, Complainte des mères criminelles. Meurtre épouvantable de huits enfants assassinés par une mère sans entrailles. 1887. Sur l'air de Béranger à L'Academie. Te souviens-tu? Paris, Maison Baudot 1887.BNF. QZ - 36-4. 
6. Aizkora kausitu du odolez bethia,

Hirurgarren haurraren hiltzerat abia,

Aitak egin ez balu etxerat jitia,

Hartaz hil behar zuen alaba Maria!

7. Etxia mia eta aitaren xagrinak,

Bi aingeru gaixuak emaztiak hilak!

Ordian hasi dira marrazka saminak!

Auzoko jende hunek ikhusirik krimak.

8. Zaharrek erran dute kontsideraturik,

Ez dutela aditu nehon halakorik,

Amak bere esnetik umiak hazirik,

Aizkora trixte batez ezarririk hilik.

9. Preso ezarri zuten Ama kriminela,

Gaizki egilendako lekhua han dela,

Bai eta kondenatu gilotinatzera,

Holako amarentzat ez dela sobera.

10. Kondenatu onduan semia galdatu,

Hil gabetarik nahi zuen besarkatu,

Haurrak aitari eman hola arrapostu:

— Ez dut ikhusi nahi, ni ere hilen nu.

11. Jujatu izan dute Tarben asisetan,

Eta gero ezarri kaxote batetan,

Urrikitan sar dadin azken egunetan,

Nahi badu parterik gero zeruetan.

12. Azken eguna jina, presta gilotina,

Direkturra bisitan kaxoterat jina, 
Behar zuela egin ongi etsamina

Erraiterat jin eta kausitu du hila !!!

\section{$\mathbf{X}$}

APHEZ POZOINDATZALEA ${ }^{113}$

\section{KANTU BERRIAK \\ PERPIGNAKO ONDUAN HOGOI ETA ZORTZI URTHEKO \\ APHEZ BATEK BI AHIZPA POZOINDATURIK}

Airia: Nahi gabe anhitz da mundian gerthatzen

1. Espainako fronteran hiri bat Perpigna,

Han egin izan dute krima lazgarriena,

Aphezak egiteko obra ederrena,

Bi ahizper eman du tristiak pozoina.

2. Aphez ernegatu bat dute kondenatu,

Ordena galdu eta burdinak baititu,

Bere denbora guzia han behar higatu.

Errientsa ${ }^{114}$ batekin nahi zen ezkondu.

3. Aphezak erraten zakon ezkondu, ezkondu,

Hartu zuen ordenaz eman orde kondu,

Zier begira daude horrenbertze mundu,

Tribunalak nahi du galeraz lagundu.

4. Mundu hau nahi nuke sujetaz argitu,

Bi ahizpa mutxurdin ditu pozoindatu,

${ }^{113}$ BNF, Fol. WZ, 700. Bertso-paperak aphaiz baten irudia dakar, bertsoak Manex (Joanes) Etcheparek sinaturik datoz, hots, Manex eta Jean Etchepare pertsona bera lirateke.

114 Errientsaren izena Alexandrine Vernet (1856-1931) zen. 
Ez dutelakotz nahi apheza behatu,

Heien hiltzia zuen ordian phentsatu.

5. Lehen biktimak zuen Maria izena,

Hari eman baitzuen ohian pozoina,

Bigarren ahizpari athera fortuna,

Sekulakotz galdu zen ordian gizona.

6. Aphezaren etxian Rosa zen egoiten,

Biziaren galtzia etzuen phentsatzen,

Bazkaritian baitu pozoina prestatzen,

Eta haren basuan Aphezak emaiten.

7. Biktimen ontarzuna ordian du saldu,

Espainiako bidia ementuan ${ }^{115}$ hartu,

Jandarmeriak zuen garan ${ }^{116}$ arrestatu,

Mala ${ }^{117}$ baten barnian dirua harrapatu.

8. Esku sakratuetan tratamendu hori,

Arropa horrendako ez baitzen konbeni,

Zer krima egin duen baita harrigarri,

Aphez horren gainian exenplu har bedi.

9. Bihotzian bazuen pena ezkontzeko,

Egointen $^{118}$ ahal baitzen ordena hartzeko,

Ora jin da tenoria nigar egiteko,

Urrikalmendu gati Aphez horrendako.

10. Mundu huntako denbora galeraz galera,

Oraino ez du aski krimaren arabera,

\footnotetext{
115 Ementuan (sic), mementuan.

116 Gara (< gare, fr.), geltokia.

117 Mala (< male, fr.), maleta, poltsa handia.

118 Egointen (sic), egoten.
} 
Nola menturatu zen jaunaren legera,

Ordena sakratia errezibitzera.

11. Joseph Auriol ${ }^{119}$ zira zegur malorosa,

Galdu duzu arima zure erresusa,

Zeruko jinkoari egiozu adresa,

Horren barkhamendutan zitzan mortifika ${ }^{120}$.

12. Bi belhain buluziez herrestan bidian,

Oihan eta desertu guzien artian,

Hilik behar zira tristia mundian,

Nahi baduzu parterik Zeruko-lorian.

13. Heskual herrian daude Aphezak fidelik,

Begiez lurrera eta bihotzez gorarik,

Penitentzia egiten dute umilki alegerarik,

Beren esku sakratiak liburu saindua betherik.

\section{PERPIGNAKO ASISAK}

Hogoi eta zortzi urtheko aphez bat sekulako galetarat $<$ k>ondenaturik, bi ahizpa mutxurdin pozoindaturik

\section{EXPLIKAZIONIA}

Perpignako onduan bada herri bat Nohèdes deitzen dena, han egoiten zen erretor bezala Jospeh Auriol hogoi eta zortzi urtheko aphez bat. Malerus hura eskolatu zuten bere borondatiaren kontra.

119 Joseph Auriol (Salses 1853 - ?) Nohèdes-eko herrixkan (Ekialdeko Pirineoak) apaiz, bi pozoinketez akusatua izanik betirako galeretera zigortu zuten.

120 VI-13-ko bertsolerro berdintsua. 
Kasu emazue zer den aphez gaizto egitia.

Bertze anhitzek bezala maite zituen emaztiak. Hortako nahi zen aphez arropa utzi herriko errientsarekin ezkontzeko.

Bazen herri hartan bi ahizpa mutxurdin lehena Marie Fonda 49 urtheko bat eta bigarrena Rosa 45 urthekua.

Miserable hak ukhan du idei gaixtua heien pozoindatzeko, eta heien fortunaren izaiteko.

Marie pozoindatu eta Rosari eginazten du testamen bat, emaiten dute beren fortuna ondar bizi denari.

Testamenta egin eta hameka egunen bazkariten ari zirelarik aphezaren etxian pozoindatzen du hura ere.

Saltzen du egun berian huntarzun guzia. Espainialat partitzen da, errientsa juan zen lehenik eta ez dute sekula hatzeman. Pradeko garan aphez izan da arrestatuia. Hatzeman diote malan fortuna guzia. plia!!!

Perpignako asisetan izan da sekulako galeretarat kondenatua. Zer exen-

Aphezak dira gizonak bertziak bezala. Bada hetan gutan bezala onak eta tzarrak. Maithatu behar dira emaztiak bainan ez pozoindatu. Nik ere segurki maite ditut, bainan ez hiltzeko.

Ez da Auriol apheza pozoindatzale bakharra. Istoriak erraten du Pelage 1er eta Alexandre Borgia ere.

Alexandre Borgiak ezkondu zuen bere alaba Lucrèce deitzen zena, de Pesaro deitzen zen aitasun batekin, eta mundian egiten ahal diren zikinkeriak egin eta bere alabarekilan, gero pozoindatu.

Ohoin, asasinatzale, pozoindatzale eta bertze ainitz zikinkeria egin zuen Alexandre VIak aitasainduak.

Ez dut segurki phentsamendurik sujet horien explikatzeko.

Maitha dezagun gure Errelijiona, eta gure jainko-jauna, eta aphezek egiten badute gaizki hainbat gaizto berentzat.

Emazteki gaixuak, etzuztet segurki exortatu nahi aphezen ez maitatzia, bainan kasu emazue zuen burueri.

Biarritz et Bayonne. Imp. Ch. Bauxon 
XI

\section{BOTIKARIO MUTHILAREN ASASINATZEA ${ }^{121}$}

Airia: Aita saldu nиzu idi bat bezala

1. Eguna argitzen da iguzki aldetik,

Nola egiten duen jaunak guregatik,

Sujet hori jin baitzait orra Parisetik,

Krima itsusienak baitira ondotik.

2. Entzutia bera ere ikharagarri da,

Aski da egoitia obrari begira,

Gizonak nola nahi jalgitzen badira,

Lanjeros denarentzat abisak badira.

3. Huna beraz sujeta Parisen agertu,

Urupa guzietan baitira harritu,

Gizona galtzeraino dute inganatu,

Bi aneiek hil eta andriak argitu.

4. Botikario batian Aubert zen muthila,

Madamarekilan zen jaun hori akorta,

Senharrak jakin zuen haien bian segreta,

Ordian egin dute hiruek konplota.

5. Pariseren onduan hiri bat Versaille,

Horien bien artian krima egin dute,

Hiru miserabliak akort ziren fite,

Gizona hil onduan garrotatu dute.

${ }^{121}$ BNF, Fol. WZ-700. Titulu osoa hauxe da: Bigarren suyeta. Pariseren eta Versaillen artian Botik $<a>$ io muthil bat assassinaturic.Sinaturik: Manech Etchepare. 
6. Karro batian ezarri plomuz kargaturik,

Bai eta ahua josi phentsatu gaberik,

Urian hatzeman dute gizona usteldurik,

Zer martier juan da gaixua mundutik.

7. Gizona kontsomitu mila inganioz,

Eta beren buruak bethikoz maloros,

Azione gaixtua zenbat den lanjeros,

Ongi gobernatzia ez denez agrados.

8. Inbide gaixtuan gizona hiltzera,

Batek igorri dako lantza bihotzera,

Arima phartitu da Eternitatera,

Jaunak errezibitu besuen artera.

9. Hirur kriminel ziren emaztiarekin,

Uros izanen ziren ez balute jakin,

Marteilu ukhaldika bertzia lantzarekin,

Obra manifikua zuten elgarrekin.

10. Senharra gilotinatu, andrie galeretan,

Oihu egiten zuten bainan alferretan,

Heiagora marraska bazen karriketan,

Gaztigu ederra da andre ezkonduetan.

11. Gizona harritzen du hiltzeko orenak,

Begien aitzinian ikhusten duenak,

Oihu eta marraskaz aita eta amak,

Hamar mila arima nigarrez zaudenak.

12. Arima phartitzen du jaunaren eskura,

Miserikordia galdez eternitatera, 
Ez duen sobera andriak galera,

Tribunalak egin du obren arabera.

VERSAILLEKO ASISAK

PARISEN ETA VERSAILLEN ARTIAN BOTIKARIO MUTHIL BAT ASASINATURIK.

\section{EXPLIKAZIONIA}

Mundu huntako krima guzien segida emaztia da. Parisen bazen Feneyrou botikario bat. Ezkondua zen. Bazuen muthil bat Aubert deitzen zena. Etxeko andria akort zen muthilarekilan. Hirur urthe egonik han muthil badua botikario bere gain. Senharrak jakiten du emaztiaren eta muthil ohiaren manobra guziak.

Senharrak erraten dio emaztiari:

- Informatia nun hire eta Auberren segretu guziez. Behar dun juan harenganat eta gomitatu gau batez promenada baten egitera Parisen eta Versaillen artera.

Aubertek errefusatzen du. Emaztiak inganatzen du eta hitz ematen dio baietz.

Bi aneiak harmaturik bata marteil batez eta bertzia lantza batez juaiten dira gau lazgarri hartan gizonaren hiltzera.

Aubert badua andriarekin. Sartzen da ganberan. Bi gizonek hiltzen dute emaztiak argi eginez.

Ahoa josten diote eta plomuz estekaturik karro batian ezartzen eta urerat botatzen.

Zonbeit egunen burian, langile batek hatzeman du Auberren gorphutza arras usteldua.

Hirur brigantak izan dira arrestaturik. Versaillen asisetan Feneyrou kondenatu dute gilotinarat, haren aneia sei urtherendako eta andria sekulako galeretarat.

Emaztekia, zendako, jainkoak eman zaitu mundurat? Gizonaren galtzeko.

Sortzeik, jainkuak gizona egin zuen bekhaturik gabe. Evaren lehen bekhatua izan da munduko lehen inbidia.

Emaztekia, khasu emazu, zaude zure esposari fidel, nahi bazira mundian izan uros, eta nahi baduzu zure familia jainkoaren beldurrian biziazi.

Har zazue emazteki guziek sujet huntan exenplu. 


\section{XII \\ AGUER-MIZPIRATEGUIREN KRIMA ${ }^{122}$}

Airia: Pena dut eta dolore

1. Gizon gazte kriminel bat heskualduna

Atharratzeko onduan egon dena.

Aguer-Mizpirateguy baitu hak izena,

Kantuz esplikatu nahi dut haren krima.

2. Hogoi eta bederatzi urthe ditu,

Licq Athereyko herrian baitzen sorthu,

Amak zuen haurretik gaizki gobernatu,

Hogoi urthe bethe artio menazatu.

3. Xortia thiratu eta soldadu zen,

Haren xerbutxuak gitu estonatzen,

Frantziako bandera zuen ohoratzen,

Askotan hola ikhusten da onak galtzen.

4. Bordeleko hirian zen Aguer sarthu,

Andere gazte batekin aiskidetu,

Behar direla elgarrekin esposatu,

Julietek bere burua konfidatu.

5. Juliet gaixua hil du tronpaturik,

Diru puska bat eskuan ikhusirik,

Promenatzerat ereman du bazkaldurik,

Moltsa har eta han utzi du gero hilik.

${ }^{122}$ Titulu osoa: Aguer-Mizpirateguin cantu berriac. Imp. Gadrat Ainé, Foix (sd.), 1889, BNF GR FOL-LN16-14. BNF, Fol. WZ 700, Don Bibliothèque Mazarine 9476. 
6. Emaztegai gaixua zuen inganatu,

Lekhu ilhun batetarat ereman du,

Sei ukhaldiko pixtoletaz porroskatu,

Arroila baten barnian gero ezarri du.

7. Lekhu guzietan kurri jaun fakturra,

Harek atzeman izan du gorphutz hura.

Zer heriotze lazgarria ! Zer malurra !

Manera hartan funditzia kreatura.

8. Espanialat nahi zen Aguer sarthu,

Oihanez oihan gordeka eskapatu,

Hamar egun trixtiak zuen han pasatu,

Erdi biluzia baitute arrestatu.

9. Hamar jandarma brigada oihanian

Aguer hatzeman baitute sasi-pian,

Xakhur batek atheratu du aintzinian,

Ez baitzen haizu egoitia zen tokian.

10. Langiliak harmaturik jandarmekin

Haren ondotik zabiltzan fusilekin,

Bi tiro eman deraizkote bolborekin,

Bai eta gero amarratu burdinekin.

11. Bordeleko asisetan da jujatu,

Juje guziek hiltzerat kondenatu,

Carnot ${ }^{123}$ presidentak gero du graziatu,

Gilotina etzuen nahi xerbutxatu.

${ }^{123}$ Sadi Carnot, 1837ko abuztuaren 11 an Limoges-en jaioa eta 1894eko ekainaren 25ean, Frantziako presidenta zelarik hila Caserio anarkista italianoaren tiroz. 
12. Galeretan eman dute sekulako,

Bere krima lazgarriaz orhoitzeko,

Exenplu handia hori da gaztendako,

Kriminelak nola dituzten tratatuko ${ }^{124}$.

\section{AGUERREN KRIMAREN ESPLIKAZIONIAK}

Aguer- Mizpirateguy sorthu zen Atharratzen eta Maulen artian, Licq Athereyko herrian. Gazterik izan zen bere amaz gaizki gobernaturik. Orok badakite Aguerren bizia. Hogoi urthetarako xortia thiratu eta partitu zen soldado. Egin du bere xerbutxia fidelitate eta oneskeria handirekin. Xerbutxua finitu onduan jiten da Maulerat, bainan amak zuen bere semiaz artha guti hartu.

Aguer badua Bordeleko hirirat. Han egon da zapur-ponpier ${ }^{125}$ bezala eta gero kai batian muthil. Toki guzietan Aguer konportatu da oneski.

Maleruski beretzat egin zuen Juliette Andrieuren ezagutza. Neska gaixo hori ezarri zuen esperantxetan eta hitz emaiten dio emazte-gaiari esposatzeko. Gaixuak ukhan du Aguer-baithan konfidenxia eta erraten dio bazuela zazpi ehun libera.

Igande egun batez bazkariten dire elgarrekin eta Aguerrek eremaiten du Juliette promenada baten egitera, eta han du sei ukhaldiko pixtolet batekin hiltzen, eta haren bisaia bolboraz porroskatu eta arroila batetarat botatzen.

Biharamunian faktur batek hatzeman du Julieten gorphutza. Aguer eskapatzen da bere ustez Espainarat. Hamar egunez egon da Landeko oihanetan gorderik, kasik buluzgorri zen eta gosia tripan, jandarmiak eta laborarioak zituen ondotik. Xakhur batek du atzeman.

${ }^{124}$ Testuak frantsesez honela jarraitzen du: Publiée para J. ETCHEPARE. Prix 20 centimes. Cour d'Assises de la Gironde. Condamnation à mort d'AGUER di< $<>$ LE BASQUE. Eta hona nola bukatzen duen frantsesez idatzi konplainta

12. Aguer, le miserable

Tu échappes à la mort

Assassin exécrable,

Tu subira ton sort.

Tu passera ta vie

Dans le Caledonie,

Loin des honnêtes gens.

À la fleur de ton âge

Cayenne est ton partage,

Voilà ton chatiment.

${ }^{125}$ Zapur-ponpier, su-hiltzaile. 
Bordeleko asisetan dute hiltzerat kondenatu. Carnot, gure Presidentak graziaturik igorri du sekulakoz galeretarat.

Hogoi eta beateratzi ${ }^{126}$ urthetan pasatu behar da bizia burtinetan. Zer exenplua !!!

Foix. Impr. Gadrat Aîné.

\section{XIII \\ DOGA BURU-PIKATZAILIA ${ }^{127}$}

Lau punduko airian

1. Doga ${ }^{128}$ gizon zarra zen eta famatua,

Cazaboneko ${ }^{129}$ hiri handian sorthua,

Jende hiltzeko zuen lurreko gostua,

Proba ezin eginez bethi libratua.

2. Bi krima egin ditu gazterik herrian,

Bihotza tristatzen da hori erraitian,

Segeret egin lanak oro azkenian

Nonbeit agertzen dira gutien ustian.

3. Bietan libratu da ezin phoroatuz,

Jendek hiltzen ari zen ongi segeretuz ,

Zer ari da gizona arima kolpatuz,

Girixtino laguna gaizki gobernatuz.

4. Ondar gerlan soldado xerbutxatua zen,

Gero jandarme sarthu onduan Parisen,

${ }^{126}$ Beateratzi (sic), bederatzi.

127 Imp. Gadrat Ainé, Foix (sd.), 1889, BNF GR FOL-LN16-14. Xabier Kaltzakorta, «Jean Etchepareren cantu dolorosac». KARMEL n. ${ }^{\circ}$ 230, 35-55- 2002.

${ }^{128}$ Doga (sic), alegia, Jean Dauga hiltzailea.

${ }^{129}$ Cazaubon (Gers). 
Jandarme bat han hil du, lekhukorik etzen,

Abilizia zarrez hala zen libratzen.

5. Doga kasatu dute jandarmeriatik,

Zarra bethi kanpo da, gizonen artetik,

Mundu huntan sobera trebatuz geroztik,

Ez ditake balia abileziatik.

6. Krimak eginak eta nehor ez ageri,

Doga bethi ixilik jende hiltzen ari,

Orai ez gira beldur gehiago hari,

Ongi segurtaturik baitute ezarri.

7. Zulzer deitzen zen jaun bat gizon galanta zen,

Bere esposarekin ari bazkariten,

Dogak hek ere ditu han berian hiltzen,

Bizar-nabala batez burua pikatzen.

8. Oben gabiak badu bethi zerbait pena,

Eta askotan libro bekhatoros dena,

Nork behar du phentsatu halako orena,

Holako gizonak du galtzen bai arima.

9. Pariseko poliza xerkha abiatu,

Doga behar dutela nonbait harrapatu,

Espetorrak hatzeman eta arrestatu,

Gaizki eginak orai behar tu pagatu.

10. Azkenian galtzen da gaizki dabilana,

Ez dea harrigarri Dogak egin lana,

Burua pika eta eskapa gizona,

Anhitz sofritzen dugu gure Jesus jauna. 
11. Nancyco asisetan baitute jujatu,

Doga dute hiltzerat jujek kondenatu,

Hiltzia deuse ez da, arima du galdu,

Ifernurako bortha berak du zabaldu.

12. Gauzarik hoberena munduko bakia,

Harek luzatzen baitu gizonen bizia,

Abandona dezagun guziek gaizkia,

Aise irabazteko Zeruko Loria.

\section{DOGA BURU-PIKATZAILIAREN IXTORIOA}

Tarbetik urhuntxago da Gers deitzen den departamendua, departamendu hartan bada hiri eder bat Cazabou deitzen dena.

Doga gizon famatu hori han sorthu zen. Orai duela hogoi urthe, bere herrian egin zituen bi krima lazgarri. Doga dute arrestatzen, eta Auch-eko asisetan izan da libraturik, zeren ez baitzen lekhuko segurrik.

Ondar gerlan egin du xerbutxu; hantik athera eta, Parisen dute Doga jandarme emaiten. Han hil-omen zuen jandarme lagun bat, bainan ez baitzuten phoroantxarik, kanporat emaiten dute jandarmerietarik. (Holako jandarmiak dira Frantzian arrado).

Geroztik Dogak egin dituen krimak dira harri-garri. Hogoi eta zortzi heriotze ditu egin. Jendiak hil eta zuen heier buruak pikatzen bizar nabala batekin.

Pariseko Poliziako Espetor batek du Doga arrestatu. Nancy-ko asisetan, Doga izan da hiltzerat jujaturik. Segurki ez du gilitina ${ }^{130}$ ebatsi, aspaldian zuen merexitua.

HESKUALDUN LAGUN MAITIAK, GUZIEK HAR DEZAGUN SUJET HORIETAN EXENPLU.

130 gilitina (sic), gilotina. 